\title{
Rapid and highly sensitive analysis of chlorophylls and carotenoids from marine phytoplankton using ultra-high performance liquid chromatography (UHPLC) with the first derivative spectrum chromatogram (FDSC) technique
}

\author{
Koji Suzuki ${ }^{1,2^{*}}$, Akiko Kamimura ${ }^{1,2}$, and Stanford B. Hooker ${ }^{3}$ \\ ${ }^{1}$ Faculty of Environmental Earth Science, Hokkaido University, North 10 West 5, Kita-ku, Sapporo \\ 060-0810, Japan \\ ${ }^{2}$ CREST, Japan Science and Technology Agency, North 10 West 5, Kita-ku, Sapporo 060-0810, Japan
}

${ }^{3}$ NASA Goddard Flight Space Center, Greenbelt, Maryland 20771, USA

*Corresponding author: E-mail: kojis@ees.hokudai.ac.jp

Keywords: Algal pigments, Chlorophylls, Carotenoids, Marine phytoplankton, Ultra-high performance liquid chromatography (UHPLC), First derivative spectrum chromatogram (FDSC) 


\section{ABSTRACT}

We developed a rapid and highly sensitive analytical method for chlorophylls and carotenoids derived from marine phytoplankton using ultra-high performance liquid chromatography (UHPLC). High-performance liquid chromatography (HPLC) has been widely used in phytoplankton pigment analysis since the 1980 's for estimating the abundance, composition, and photosynthetic physiology of natural algal assemblages or laboratory cultures. However, the run-time of the HPLC analyses is generally ca. 30 min or more, which is time-consuming for analysts. Our UHPLC technique enabled us to complete the separations of chlorophylls and carotenoids from marine phytoplankton within 7 min with similar resolution as conventional HPLC methods. The analytical method was tested on authentic pigment standards, marine phytoplankton cultures, and field samples that were collected from the central tropical and subarctic Pacific plus the neritic Bering Sea. Critical pigment pairs that generally co-eluted as a single peak were successively resolved by obtaining the first derivative spectrum chromatograms (FDSCs) with a photodiode array (PDA) detector based on differences in pigment absorption spectra, e.g., chlorophyll (Chl) $c_{2}$ and $\mathrm{Mg} 2,4$ divinyl (DV) pheoporphyrin $a_{5}$ monomethyl ester (MgDVP), as well as DVChl $b$ and $\mathrm{Chl} b$. Because the maximum injection volume of UHPLC is generally lower than that of HPLC to minimize the unwanted broadening of chromatographic peaks, the detection sensitivity needed to be increased, especially for oligotrophic seawater samples with low pigment concentration. To overcome this sensitivity issue, a PDA detector equipped with an $85 \mathrm{~mm}$ path length capillary cell was used with a fluorescence detector. As a result, the limit of quantitation (LOQ) as determined by absorbance was of the order of $0.1 \mathrm{ng}$ for chlorophylls and carotenoids. Furthermore, a bead-beating technique using $N, N$-dimethylformamide (DMF) and zirconia beads was used to minimize the volume of the organic solvent used for pigment 
1

2 extraction. Our UHPLC method can replace the conventional HPLC techniques, and allows us to yield high-throughput data of the chlorophylls and carotenoids derived from marine phytoplankton. 


\section{Introduction}

Chlorophylls and carotenoids play a crucial role in absorbing and transferring light energy for the photosynthetic processes of marine organisms (Falkowski and Raven, 2007). In oceanic surface waters, chlorophyll (Chl) $a$, the principal photosynthetic pigment, is generally derived from eukaryotic phytoplankton and cyanobacteria, apart from the cyanobacterium Prochlorococcus (Chisholm et al., 1988), which contains divinyl (DV) Chl $a$ (DVChl $a$ ). The photosynthetic organisms also have a variety of accessory pigments, which enable them niche differentiation in underwater light spectrum (Stomp et al., 2007). Chlorophylls $b$ and $c$ are major accessory pigments in green and red algal lineages, respectively (Delwiche, 1999). Jeffrey and Wright (2006) reported patterns of 16 chlorophylls, 37 carotenoids and 3 phycobiliproteins across 32 marine algal groups, supporting the endosymbiotic theory of the origins of plastid diversity (Hackett et al., 2007). Based on the origins of plastids, algal pigment data from field samples can provide pivotal information on the abundance and taxonomic composition of phytoplankton assemblages, especially in oligotrophic waters where the predominance of tiny algal cells are challenging to identify with microscopy. Recent rapid advances in next-generation sequence (NGS) technologies have enabled the examination of detailed community composition of a specific marine phytoplankton group (e.g., Bittner et al., 2013). Lack of a universal primer pair specifically for marine phytoplankton (cyanobacteria and eukaryotic microalgae), however, prevents a description of their total in situ community structure using NGS technologies (e.g., Hadziavdic et al., 2014). Algal pigment signatures considered within multivariate analyses, such as CHEMTAX (Mackey et al., 1996), can yield a total phytoplankton community structure at class level in terms of Chl biomass. Furthermore, such $\mathrm{Chl}$ and carotenoid data were applied to estimate 
phytoplankton functional types in the world ocean through satellite ocean color remote sensing (e.g., Hirata et al., 2011).

To separate and quantify the chlorophylls and carotenoids from marine phytoplankton, high-performance liquid chromatography (HPLC) has been widely used since the 1980's. Garrido et al. (2011) summarized the methods proposed for the analysis of phytoplankton pigments with HPLC after 1991. In the last two decades, the recognition of the taxonomic and physiological importance of certain pigments not previously separated has stimulated the development of new HPLC methods. For example, reverse-phase HPLC with $\mathrm{C}_{8}$ monomeric columns has enabled the separation of a variety of carotenoids, as well as the partial resolutions of chlorophylls from their corresponding DV forms (e.g., Barlow et al., 1997; Zapata et al., 2000; Van Heukelem and Thomas, 2001). Recently, Jayaraman et al. (2011) achieved the complete separation of DVChl $b$ from Chl $b$ and almost complete resolution for the DVChl $a$ and Chl $a$ pair in marine phytoplankton using a $\mathrm{C}_{16}$-Amide column. More recently, Sanz et al. (2015) succeeded in the complete resolution of monovinyl and DV forms of chlorophylls $a, b$, and $c$ in marine phytoplankton with a pentafluorophenyloctadecyl silica column. The HPLC techniques of Jayaraman et al. (2011) and Sanz et al. (2015) were also capable of the resolution of chemotaxonomically important carotenoids. Thus HPLC pigment analysis has advanced for estimating the biomass and composition of phytoplankton assemblages in aquatic ecosystems. Inter-calibration exercises of HPLC pigment analysis have also been carried out for data quality assurance and control among laboratories (e.g., Claustre et al., 2004; Hooker et al., 2012). The HPLC analysis of pigments is also an indispensable technique for photosynthesis studies on the structures and functions of antenna systems in photosynthetic organisms or the metabolisms of chlorophylls and carotenoids (e.g., Lu and Li, 2008; Tanaka and Tanaka 2011). However, the run-time of most HPLC 
methods is generally ca. $30 \mathrm{~min}$ or more to obtain sufficient pigment resolution (see Garrido et al., 2011; Jayaraman et al., 2011; Sanz et al., 2015), which is time-consuming for analysts. In addition, because phytoplankton pigment samples stored in freezers can be degraded with time (Mantoura et al., 1997), pigment analyses should be carried out as soon as possible after sampling.

Recently, HPLC columns with particle sizes less than $2 \mu \mathrm{m}$ have been developed in response to the increasing demand from industry to shorten analysis times and increase data throughput (Cabooter and Desmet, 2012). To operate these columns at or above their optimal flow rate, instrumentation that is capable of delivering pressures above $40 \mathrm{MPa}$ (up to ca. $130 \mathrm{MPa}$ ) has become available under the name of ultra-high performance liquid chromatography (UHPLC). Decreasing the particle size by a factor of 2 (i.e., from $3.5 \mu \mathrm{m}$ to $1.7 \mu \mathrm{m}$ ) increases the backpressure by a factor of 4 at a constant linear velocity (Fountain et al., 2009). Additionally, the linear velocity at the minimum of the van Deemter curve increases as particle size decreases, which at optimum linear velocity causes the pressure to increase with a decrease in particle size cubed (MacNair et al., 1997). For a two-fold decrease in particle size, the backpressure at optimal flow actually increases by a factor of 8 (Fountain and Iraneta, 2012). Also, UHPLC system require minimal extra-column band spreading and gradient delay volume (also known as dwell volume), which are defined as the unwanted broadening of a chromatographic peak from the point of injection to the point of detection and the volume between where the gradient is formed and the inlet of the column, respectively (Fountain and Iraneta, 2012) in which narrower (e.g., $0.1 \mathrm{~mm}$ inner diameter) PEEK or stainless steel tubing are used at appropriate places. The term UPLC ${ }^{\circledR}$ is sometimes used instead of UHPLC and is trademarked by Waters Corporation, which introduced the first commercially available UHPLC in 2004. Consequently, the more generic term UHPLC is used in this study. However, as far as we know, no methodological paper 
has been published on the UHPLC analysis for chlorophylls and carotenoids from phytoplankton assemblages in the ocean. Recently, Fu et al. (2012) and Pacini et al. (2015) introduced powerful techniques for analyzing chlorophylls and carotenoids in phytoplankton cultures using UHPLC combined with UV-VIS detection and mass spectrometry. The run-time of their UHPLC systems was $20 \mathrm{~min}$, but the resolutions of polar pigments such as the $\mathrm{Chl} c$ group and peridinin (Peri) were not reported in Fu et al. (2012) and Pacini et al. (2015). Although UHPLC has the potential to achieve faster and higher resolution analyses, the maximum sample injection volume of UHPLC is generally lower than that of HPLC to minimize the extra-column band spreading. The lower injection volume of UHPLC can hinder the detection of trace amounts of phytoplankton pigments in field samples. In particular, algal pigment concentrations in oligotrophic oceanic waters are generally very low (e.g., Ras et al., 2008). Therefore, the low sensitivity issue needs to be solved for such diluted samples in the UHPLC pigment analysis.

Here, we present a novel method for the rapid and highly sensitive analysis of chlorophylls and carotenoids from marine phytoplankton with UHPLC, which enabled us to complete the separations of these pigments within 7 min with similar resolutions as conventional HPLC methods. To resolve the sensitivity issue mentioned above, a PDA detector equipped with an $85 \mathrm{~mm}$ path length capillary cell was used with a fluorescence detector. To establish the methodology, authentic standards and the pigments from representative marine phytoplankton cultures were tested, followed by the analyses of field samples that were collected from the central tropical and subarctic Pacific and the neritic Bering Sea during the summer of 2014. Furthermore, based on differences in pigment absorption spectra, we succeeded in resolving critical pigment pairs (e.g., DVChl $b$ and $\mathrm{Chl} b$ ) that generally co-eluted as a single peak on chromatograms by obtaining the first derivative spectrum 
chromatograms (FDSCs) with a photodiode array (PDA) detector (Yamamoto et al., 1995). Recently, Yanagisawa (2014) succeeded in quantitating co-eluted peaks consisting of difluorobenzophenone and valerophenone using the FDSC technique. As far as we know, this study is the first report of the application of the FDSC technique for marine phytoplankton pigments.

\section{Materials and methods}

\subsection{Marine phytoplankton cultures and field samples}

The marine phytoplankton cultures used in this study with their culture media and incubation temperatures are listed in Table 1 . All of the strains, except for the cyanobacterium Trichodesmium erythraeum CCMP1985, were cultured under low-light conditions (10-40 $\mu$ mol quanta $\mathrm{m}^{-2} \mathrm{~s}^{-1}$ ) with a white fluorescent lamp (FL20SSN/18, NEC Corporation/Kotobuki) under a $12 \mathrm{~h}$ light and $12 \mathrm{~h}$ dark cycle, whereas the Trichodesmium strain was grown at $100 \mu \mathrm{mol}$ quanta $\mathrm{m}^{-2} \mathrm{~s}^{-1}$ from white LEDs (Luxeon LXHL-BW03, Philips Lumileds Lightning Co.) under a $12 \mathrm{~h}$ light and $12 \mathrm{~h}$ dark cycle. All of the phytoplankton cultures were harvested by filtering within 3 weeks after the start of culturing in new media. The culture samples $(2-15 \mathrm{~mL})$ were filtered onto $25 \mathrm{~mm}$ Whatman $\mathrm{GF} / \mathrm{F}$ filters (nominal pore size $0.7 \mu \mathrm{m}$ ) with gentle vacuum $(<0.013 \mathrm{MPa})$. The obtained filters were kept in a freezer at $-80^{\circ} \mathrm{C}$ and used within a few days for analysis.

Field samples were collected at a depth of $5 \mathrm{~m}$ from stations (stns.) A, B and C (Fig. 1) in the central tropical and subarctic Pacific and the neritic Bering Sea (30 m water depth) off Alaska, 
USA, respectively, and from the subsurface chlorophyll maximum (SCM) layer (136 m) of stn. A using a CTD-CMS (carousel multi-sampler system) attached with X-Niskin bottles during the R/V Hakuho Maru KH-14-3 expedition (JAMSTEC and University of Tokyo) in July 2014. Duplicate seawater samples (each 2,340 mL from stn. A and each 1,190 mL from stns. B and C) were filtered onto $25 \mathrm{~mm}$ Whatman GF/F filters with gentle vacuum $(<0.013 \mathrm{MPa})$. The obtained filters were stored in liquid nitrogen or a freezer at $-80^{\circ} \mathrm{C}$ and used within 3 months.

\subsection{Pigment extraction}

Phytoplankton pigments were extracted using the bead-beating technique (Mock and Hoch, 2005; Wright et al., 2010) with a few modifications. The GF/F filters were cut into small pieces with clean scissors and soaked in $1 \mathrm{~mL}$ of HPLC-grade DMF (Wako Co., Ltd.) in which a known amount of trans- $\beta$-apo- 8 '-carotenal (Sigma-Aldrich), hereafter Apo, as an internal standard was contained and stored in $2 \mathrm{~mL}$ conical-shaped micro-tubes with silicon-rubber-O-ring-equipped screw caps (1392-200-C, Watson Co., Ltd.) at $-30^{\circ} \mathrm{C}$ for $1 \mathrm{~h}$. The scissors were cleaned with ethanol (Wako Co., Ltd.) and then wiped with Kimwipes (Kimberly-Clark Corp.) or Prowipe S200 (Daio Paper Corp.) before cutting up each filter. Additionally, $0.7 \mathrm{~mm}$ zirconia beads ( $0.6 \mathrm{~g}$, BioSpec Products Inc.), that were prewashed with methanol, rinsed with Milli-Q water and then dried, were also added to each micro-tube. No pigments were removed from the black O-ring with DMF, and the cleaning of zirconia beads was indispensable to avoid unknown peaks on chromatograms. The cells were disrupted using a Mini-Beadbeater-1 (Bio Spec Products Inc.) for $20 \mathrm{~s}$ at 4,800 rpm. The micro-tube was centrifuged for 2 min at $13,000 \mathrm{rpm}$ at $4{ }^{\circ} \mathrm{C}$ to separate pigment extracts from the filter debris, cell residues and beads. 
After the centrifugation, the supernatant was filtered through a $13 \mathrm{~mm}$ PTFE syringe filter $(0.2 \mu \mathrm{m}$ in pore size, Juji Field Inc.) to remove fine particles.

\subsection{UHPLC pigment analysis}

We used a Shimadzu UHPLC Nexera X2 SR system consisting of a CBM-20A system controller, two LC-30AD pumps, a DGU-20A 5R online degasser, a SIL-30AC autosampler with a 50 $\mu 1$ sample loop and a needle-in-loop mode that kept the sample needle in the fluid path after injection (hence the entire path was flushed with eluents to avoid any carryover), a CTO-20AC column oven, a SPD-M30A photodiode array (PDA) detector equipped with a deuterium $\left(\mathrm{D}_{2}\right)$ lump and an $85 \mathrm{~mm}$ path length capillary cell ( $9 \mu \mathrm{L}$ in volume), and a RF-20AXS fluorescence detector. Binary high-pressure mixing was conducted using the two pumps and a gradient mixer ( $20 \mu \mathrm{L}$ in volume). The gradient delay volume (dwell volume) of our UHPLC system was $145 \mu \mathrm{L}$. The settings of the SPD-M30A PDA detector were as follows: $4 \mathrm{~nm}$ bandwidth, $8 \mathrm{~nm}$ slit, $80 \mathrm{~ms}$ sampling frequency, 80 ms time-constant for data filtering, and $350-700 \mathrm{~nm}$ in detection wavelength. A conventional SPD-M20A PDA detector (tungsten (W) lamp, $4 \mathrm{~nm}$ bandwidth, $8 \mathrm{~nm}$ slit, $80 \mathrm{~ms}$ sampling frequency, $80 \mathrm{~ms}$ time-constant for data filtering, and $400-700 \mathrm{~nm}$ in detection range) equipped with a $5 \mathrm{~mm}$ path length semi-micro flow cell $(2.5 \mu \mathrm{L}$ in volume) was also used for data comparison with the SPD-M30A detector. The fluorescence detector was set as follows: excitation at $435 \mathrm{~nm}$, emission at $670 \mathrm{~nm}$, and $100 \mathrm{~ms}$ sampling frequency. An Agilent ZORBAX Eclipse Plus C8 Rapid Resolution High Throughput (RRHT) column $\left(1.8 \mu \mathrm{m}\right.$ particle size, $4.6 \times 50 \mathrm{~mm}, 95 \times 10^{-10} \mathrm{~m}$ pore size, $160 \mathrm{~m}^{2}$ 
$\mathrm{g}^{-1}$ surface area, double end-capped, and $7 \%$ carbon load) connected with a Phenomenex SecurityGuard ULTRA C8 cartridge $(4.6 \times 2 \mathrm{~mm})$ was installed in the column oven.

Following Van Heukelem and Thomas (2001), we adopted a binary solvent system consisting of Eluent A (70:30 (v:v) methanol and $28 \mathrm{mM}$ tetrabutylammonium acetate (TBAA, Sigma-Aldrich Co. LLC.) aqueous solution at $\mathrm{pH}$ 6.5) and Eluent B (HPLC-grade methanol, Wako Co., Ltd). The $\mathrm{pH}$ of the TBAA solution was adjusted with $5 \mathrm{M} \mathrm{NaOH}$. The TBAA solution was filtered through a $47 \mathrm{~mm}$ Nuclepore membrane filter $(0.2 \mu \mathrm{m}$ pore size $)$ before use. Additionally, prior to use of Eluent A, this solution was degassed with a bath sonicator $\left(300 \mathrm{~W}, 2 \mathrm{~min}, 25^{\circ} \mathrm{C}\right)$ and then purged with helium $\left(5 \mathrm{~min}\right.$, ca. $\left.300 \mathrm{~mL} \mathrm{~min}^{-1}\right)$, because air bubbles were easily generated after mixing methanol with the TBAA solution. Chlorophylls and carotenoids were separated with a linear gradient from $5 \%$ to $95 \%$ of Eluent B over the course of $5 \mathrm{~min}$, followed by an isocratic hold at $95 \%$ of Eluent B for 2 min. The flow rate was held constant at $2.0 \mathrm{~mL} \mathrm{~min}^{-1}$. The column temperature was kept at $60^{\circ} \mathrm{C}$ following Van Heukelem and Thomas (2001). The sample holder in the autosampler was cooled at $4^{\circ} \mathrm{C}$. For sample injection, pigment extract or standard sample (total $24 \mu \mathrm{L}$ ) and $28 \mathrm{mM}$ TBAA solution (total $24 \mu \mathrm{L}$ ) were sucked into the sample loop of the autosampler programmatically (Table 2) and were subsequently drawn into the column. The injection including the sample pre-treatment was conducted within $80 \mathrm{~s}$. In addition, the recovery of the initial eluent condition (95\% eluent A and 5\% eluent B) after a single run was performed within $40 \mathrm{~s}$ as estimated from pump pressure values.

For the detection and quantitation of pigments, standards were obtained from DHI Lab Products, except for the Chl $a$, Chl $b$, lutein (Lut), Trans- $\beta$-apo- 8 '-carotenal (Apo), $\beta, \beta$-carotene ( $\beta \beta$-Car) and $\beta, \varepsilon$-carotene ( $\beta \varepsilon$-Car) from Sigma-Aldrich Co. LLC, and the DVChl $b$, which is derived from a $d v r$ mutant of Arabidopsis thaliana (Nagata et al., 2005) provided by A. Tanaka (Hokkaido 
Univ.). In this study, the quantitative pigment standards from DHI were referred to as DHI-Qt standards. These pigment standards were analyzed to derive multipoint calibration curves $(n \geq 5)$ following Bidigare et al. (2005). The specific absorption coefficients of the pigment standards were determined from Roy et al. (2011) or Porra et al. (1989). Most of the pigments were generally quantified with peak areas at $436 \mathrm{~nm}$, while chlorophyllide (Chlide) $a$ was quantified at $675 \mathrm{~nm}$ because it overlapped with $\mathrm{Chl} c_{1}$ at $436 \mathrm{~nm}$ in our system, which had no absorbance at $675 \mathrm{~nm}$. In addition, we tried to separate and quantify other pigment pairs that could not be separated from each other at $436 \mathrm{~nm}$ using the FDSC technique (Sect. 2.5). Furthermore, the data from the fluorescence detector were used for the detection of chlorophylls and their degraded products.

For quality assurance and control, the DHI mixed phytoplankton pigment (hereafter DHI-Mix) standard (Lot No. mix-115), was injected at every sample queue (once before or after six unknown samples at least). The DHI-Mix standard was manufactured with an artificial mixing of pigments from algal cultured stocks of the manufacturer, and the pigments were dissolved in $90 \%$ acetone. In addition, a known amount of Apo in DMF was also used to check the condition of the UHPLC system. A mixture of the Apo and TBAA solutions was programmatically injected three times at the start of each daily sample queue. Pigments were identified by a comparison of their retention times and absorption spectra with pigment standards from DHI-Mix, DHI-Qt, and Sigma-Aldrich or with the pigments in phytoplankton cultures (Table 1).

\subsection{HPLC pigment analysis}

For comparison with the UHPLC pigment data, especially for the DHI-Mix standard, we 
adopted a conventional Shimadzu HPLC system consisting of a CBM-20A system controller, two LC-10AT VP pumps (binary high-pressure mixing system), a DGU-20 A5 online degasser, a modified SIL-20AC autosampler capable of sample pre-treatment with a $500 \mu 1$ sample loop, a CTO-10 AC VP column oven and a SPD-M20A PDA detector (W lamp, 4 nm bandwidth, $1.2 \mathrm{~nm}$ slit, $640 \mathrm{~ms}$ sampling frequency, $640 \mathrm{~ms}$ time-constant for data filtering, and 400-700 $\mathrm{nm}$ in detection range) equipped with a $10 \mathrm{~mm}$ path length flow cell $(10 \mu \mathrm{L}$ in volume). An Agilent ZORBAX Eclipse XDB-C8 Rapid Resolution column $\left(3.5 \mu \mathrm{m}\right.$ particle size, $4.6 \times 150 \mathrm{~mm}, 80 \times 10^{-10} \mathrm{~m}$ pore size, $180 \mathrm{~m}^{2} \mathrm{~g}^{-1}$ surface area, double end-capped, and 7.6\% carbon load) connected with an Agilent Eclipse XDB-C8 cartridge (3.5 $\mu \mathrm{m}$ particle size, $4.6 \times 30 \mathrm{~mm}$ ) as a guard column was installed in the column oven. The eluents and column temperature of the HPLC system were the same as those of the UHPLC described above. Following Van Heukelem and Thomas (2001), chlorophylls and carotenoids were separated with a linear gradient from 5\% to 95\% of Eluent B over the course of $22 \mathrm{~min}$, followed by an isocratic hold at $95 \%$ of Eluent $\mathrm{B}$ for $8 \mathrm{~min}$. The flow rate was set at $1.2 \mathrm{~mL} \mathrm{~min}{ }^{-1}$. The sample holder in the autosampler was cooled at $4^{\circ} \mathrm{C}$. For sample injection, the pigment extract or standard (total $125 \mu \mathrm{L}$ ) and $28 \mathrm{mM}$ TBAA solution (total $125 \mu \mathrm{L}$ ) were drawn into the sample loop of the autosampler in a similar manner as in the UHPLC technique (i.e., sample $25 \mu \mathrm{L} \times 5$ times, TBAA solution $25 \mu \mathrm{L} \times 5$ times, insert $2 \mu \mathrm{L}$ of air between sample and TBAA solution; cf. Table 2) and were subsequently injected onto the column. The methods for the identification and quantification of pigments were the same as those in the UHPLC technique described above.

\subsection{Peak separation}



defined by the difference in retention times divided by the average of peak widths were used (Wright, 1997):

$R_{S}=\frac{2\left(t_{R_{2}}-t_{R_{1}}\right)}{\left(w_{B_{1}}+w_{B_{2}}\right)}$

where $t_{R_{1}}$ and $t_{R_{2}}$ are the retention times (minutes) of peaks 1 and 2, respectively. Similarly, $w_{B_{1}}$ and $w_{B_{2}}$ are the widths (minutes) of peaks 1 and 2 at their respective bases, respectively.

For critical pigment pairs that were co-eluted each as a single peak, the FDSC technique (Yamamoto et al., 1995) was applied for the separation and quantification of these pigments with the SPD-M30A PDA detector. The FDSC technique is also referred to as Intelligent Peak Deconvolution Analysis (i-PDeA; Yanagisawa, 2014) for its product name of the manufacturer. In theory, a three-dimensional chromatogram $S(t, \lambda)$ at time $t$ and wavelength $\lambda$ for two co-eluted pigments $x$ and $y$ can be expressed as follows:

$S(t, \lambda)=p_{x}(t) s_{x}(\lambda)+p_{y}(t) s_{y}(\lambda)$

where $p_{x}(t)$ and $s_{x}(\lambda)$ are the peak profile and absorption spectrum of pigment $x$, respectively. Similarly, $p_{y}(t)$ and $s_{y}(\lambda)$ are the peak profile and absorption spectrum of pigment $y$, respectively. Using the partial derivative of $S(t, \lambda)$ with respect to $\lambda$, the FDSC at wavelength $\lambda_{d}$ can be given as follows:

$\left.\frac{\partial s}{\partial \lambda}\right|_{\lambda_{d}}(t)=p_{x}(t) s_{x}^{\prime}\left(\lambda_{d}\right)+p_{y}(t) s_{y}^{\prime}\left(\lambda_{d}\right)$

where $s_{x}^{\prime}\left(\lambda_{d}\right)$ and $s_{y}^{\prime}\left(\lambda_{d}\right)$ are the derivatives of $s_{x}$ and $s_{y}$ with respect to $\lambda_{d}$, respectively. At wavelength $\lambda_{x}$, where the maximum or minimum of the absorption spectrum for pigment $x$ occurs, namely $s_{x}^{\prime}\left(\lambda_{x}\right)=0$, the FDSC at $\lambda_{x}$ can be expressed as follows: 
$\left.\frac{\partial s}{\partial \lambda}\right|_{\lambda_{x}}(t)=p_{y}(t) s_{y}^{\prime}\left(\lambda_{x}\right)$

Similarly, at wavelength $\lambda_{y}$, where the peak maximum or minimum of the absorption spectrum for pigment $y$ occurs, namely $s_{y}^{\prime}\left(\lambda_{y}\right)=0$, the FDSC at $\lambda_{y}$ can be formulated as follows:

$\left.\frac{\partial s}{\partial \lambda}\right|_{y}(t)=p_{x}(t) s_{x}^{\prime}\left(\lambda_{y}\right)$

The $s_{y}^{\prime}\left(\lambda_{x}\right)$ term in (4) and $s_{x}^{\prime}\left(\lambda_{y}\right)$ in (5) represent the spectral slopes of $s_{y}$ and $s_{x}$ from $\lambda_{x}$ and $\lambda_{y}$, respectively, and these are constant values. Therefore, the FDSCs expressed in (4) and (5) show the elution profiles of pigments $y$ and $x$, respectively. The calculations of FDSCs are rather straightforward, so the FDSCs can be obtained in real-time during the UHPLC run. In practice, according to the manufacturer's protocol, the wavelength accuracy check of the SPD-M30A PDA detector was performed using methanol (i.e., Eluent B) and the emission line $(656.1 \mathrm{~nm})$ of the $\mathrm{D}_{2}$ lamp, and confirmed that the errors were within $1 \mathrm{~nm}$. Following the polynomial algorithm of Savitzky and Golay (1964), the wavelengths $\lambda_{\mathrm{x}}$ and $\lambda_{\mathrm{y}}$ (with two decimal places following the manufacturer's protocol) were determined in advance with the PDA absorption spectra of the authentic standards for pigments $x$ and $y$, respectively. If the values of $s_{y}^{\prime}\left(\lambda_{x}\right)$ or $s_{x}^{\prime}\left(\lambda_{y}\right)$ were negative, the values of elution profiles were multiplied by -1 for calculating their peak areas.

\subsection{Limit of quantitation $(L O Q)$}

Following Claustre et al. (2004), the limit of quantitation (LOQ) was calculated for Chl $a$ and fucoxanthin (Fuco) analyzed with the UHPLC or HPLC systems based on the amount (weight) of injected pigment corresponding to a signal-to-noise (SNR) ratio of 10 at the wavelength that was used 
for quantitation. Similarly, LOQ values were calculated for the pigments targeted in the FDSC technique in the same manner. Short-term instrument noise (Snyder and Kirkland, 1979) occurring after the elution of carotenes ( $\beta \varepsilon$-Car and $\beta \beta$-Car) in the DHI-Mix standard was used for the SNR calculations.

\section{Results and discussion}

\subsection{Choice of UHPLC column}

The Agilent ZORBAX Eclipse Plus C8 RRHT column $(1.8 \mu \mathrm{m}$ particle size, $4.6 \times 50 \mathrm{~mm})$ was used for all of the UHPLC pigment analyses in this study. The maximum pump pressure against the flow line (mainly the column) was approximately $50 \mathrm{MPa}$ in each run (cf. ca. $15 \mathrm{MPa}$ in our HPLC system). In ordinary UHPLC systems, narrow columns (e.g., $2.1 \mathrm{~mm}$ internal diameter) packed with sub-2 $\mu \mathrm{m}$ particles are often used to obtain optimum theoretical plates with a low flow rate of mobile phase (Fountain and Iraneta, 2012). Such column settings can help to reduce the volume and cost of the eluents used in UHPLC analyses. However, narrow columns would be unfavorable for the analyses of field samples with low pigment concentration, because sample injection volume can be severely limited in such narrow columns (Lestremau et al., 2010). In addition, pump pressure in such narrow columns increases in comparison to wider columns if the same flow rate, particle size, and column length are maintained. Consequently the pressure against the former columns can easily exceed the maximum set by the manufacturer. On the other hand, it is known that the wider columns are not as 
efficient at dissipating the heat generated by using small particle columns at higher linear velocities (Fountain and Iraneta, 2012). The heat produces axial and radial thermal gradients in the column, and the latter contributes to band spreading that can cause serious loss of efficiency for sub- $2 \mu$ m columns under certain high flow rate conditions (Gritti and Guiochon, 2008). Therefore, a general solution to minimizing the thermal effect is to use a narrow column for UHPLC. In this study, the column temperature was kept at $60^{\circ} \mathrm{C}$, so there could be reduced frictional heating associated with the use of $1.8 \mu \mathrm{m}$ particles and the flow rate of $2.0 \mathrm{~mL} \mathrm{~min}^{-1}$.

A longer column $(4.6 \times 100 \mathrm{~mm})$ of the ZORBAX Eclipse Plus C8 RRHT $(1.8 \mu \mathrm{m}$ particle size) was also available from the manufacturer. The longer column may produce better pigment resolutions and improve confidence in peak identification. However, pressure against the long column can easily exceed the maximum (60 MPa) set by the manufacturer if rapid pigment resolutions are pursued. Consequently, the analysis time would be significantly longer to keep the backpressure pressure low. Therefore, we did not use the long column in this study.

3.2 Comparisons of the pigment separation and its detection limit between UHPLC and HPLC techniques using authentic standards

Figure 2 shows the separations of the DHI-Mix standard with the UHPLC and HPLC techniques. The chlorophylls and carotenoids were detected at $436 \mathrm{~nm}$, which is commonly used for the detection of these pigments (Bidigare et al., 2005), and they were identified following the certificate of the DHI-Mix standard provided by the manufacturer that also used the Van Heukelem and Thomas (2001) method. The retention times and pigment separations are also summarized in 
Table 3, in which those from other pigment standards and pigments in the algal strains are also indicated.

For the HPLC chromatogram (Fig. 2A), chlorophylls and carotenoids in the DHI-Mix standard were resolved completely $\left(R_{s} \geq 1.5\right)$ or partially $\left(0.5<R_{s}<1.5\right)$ within $30 \mathrm{~min}$, except for the following pigment pairs: $\mathrm{Chl} c_{2}$ and $\mathrm{Mg} 2,4$ divinyl pheoporphyrin $a_{5}$ monomethyl ester (MgDVP), DVChl $b$ and Chl $b$, plus $\beta \varepsilon$-Car and $\beta \beta$-Car (Table 3). The resolution capability of our HPLC system was mostly similar to that of Van Heukelem and Thomas (2001) who used the absorbance at $450 \mathrm{~nm}$ for pigment detection. However, in our HPLC system, the critical pigment pair of DVChl $b$ and Chl $b$ was co-eluted as a single peak both at 436 and $450 \mathrm{~nm}$, whereas these pigments were partially resolved $\left(R_{\mathrm{s}}=0.8\right)$ by Van Heukelem and Thomas (2001). Additionally, it should be noted that, in our HPLC system, prasinoxanthin (Pras) did not separate from 19'-hexanoyloxy-4-ketofucoxanthin (Hex-kfuco), which was not contained in the DHI-Mix, but was part of our DHI-Q standards and the haptophyte strains used (Table 3). The separation problem for Pras and Hex-kfuco was also reported in Hooker et al. (2012). The resolution of polar pigments (Chl $c$ group, MgDVP and Chlide $a$ ) in $90 \%$ acetone was slightly incomplete in our HPLC system, but the use of DMF as the extraction solvent improved the separations among these pigments as in Van Heukelem and Thomas (2001).

Using our UHPLC system, similar pigment resolutions were obtained within 7 min (Figs. 2a and $2 b$, Table 3). Separations of the critical pigment pairs of diadinoxanthin (Diadino; peak 18) and dinoxanthin (Dino; peak 19) and zeaxanthin (Zea; peak 23) and lutein (Lut; peak 24) using the UHPLC technique were superior to those of our HPLC method (see the $R_{\mathrm{S}}$ values in Table 3 ). In addition, except for the unresolved pigment pairs described above, the $R_{\mathrm{S}}$ values of all of the pigment pairs in the DHI-Mix standard were $\geq 1.0$ (Table 3). According to Wright (1997), peaks with 
resolutions greater than 1.0 can be accurately quantified. Van Heukelem and Hooker (2011) also noted that a useful acceptance criterion for the performance of a new column is $R_{\mathrm{s}} \geq 1.0$ between critical peak pairs. However, the separation of 19'-hexanoyloxyfucoxanthin (Hex-fuco; peak 16) from astaxanthin (Asta; peak 17) with the UHPLC technique became worse than that of the HPLC method. It is known that a trace amount of Asta is contained in marine chlorophytes but is rarely detected in natural seawater samples unless the algal group becomes dominant (Jeffrey et al., 2011), whereas the pigment is abundant in crustaceans and salmons (López et al., 2004). Therefore, the poor resolution between Hex and Asta in the UHPLC system can be neglected in most analyses for targeting marine phytoplankton.

Compared to the UHPLC chromatogram obtained with the conventional SPD-M20A PDA detector with a $5 \mathrm{~mm}$ path length semi-micro flow cell (Fig. 2b), the detection sensitivity was greatly improved by using the SPD-M30A PDA detector with an $85 \mathrm{~mm}$ path length capillary cell (Fig. 2c). Corresponding to the differences in path length (17-fold) and other configurations between the two PDA detectors, peak areas of each pigment analyzed with the SPD-M30A PDA detector became approximately 18 times higher than those from the SPD-M20A PDA detector. Values of LOQ for Chl $a$ and Fuco as determined by the UHPLC with SPD-M30A PDA detector were $0.2 \mathrm{ng}$ and $0.1 \mathrm{ng}$, respectively, and these were lower than those with the UHPLC or HPLC with SPD-M20A, as listed in Table 4, along with the results from four laboratories in Claustre et al. (2004). The LOQ values for other chlorophylls and carotenoids detected by the SPD-M30A detector were of the order of $0.1 \mathrm{ng}$. Additionally, the LOQ for Chl $a$ determined using the UHPLC with a fluorescence detector was 0.02 ng, indicating a 10 times higher detection sensitivity compared to the SPD-M30A PDA detector. These results suggest that the PDA with a capillary cell and fluorescence detection would be useful for 
detecting trace amounts of chlorophylls and carotenoids from marine phytoplankton. Relatively high values of LOQ for Chl $a$ and Fuco in our HPLC method were found (Table 4), and this was likely due to the narrow slit width $(1.2 \mathrm{~nm})$ of the PDA detector which was specified to obtain absorption spectra at high precision.

For the repeatability of the results (i.e., injection precision) determined by the UHPLC with SPD-M30A PDA detector, the coefficient of variation (CV) values were estimated for Chl $a$ and Peri in the DHI-Mix standard ( $n=3)$, according to Hooker et al. (2012) in which Peri was chosen as an early-eluting pigment standard and to include the possible effects of peak asymmetry. As a result, the $\mathrm{CV}$ values of Chl $a$ and Peri were $0.74 \%$ and $0.30 \%$, respectively. These results were classified into the state-of-the-art performance category defined by Hooker et al. (2012).

\subsection{First derivative spectrum chromatogram (FDSC) technique}

In our UHPLC system, three pigment pairs in the DHI-Mix standard co-eluted each as a single peak: Chl $c_{2}$ and MgDVP, DVChl $b$ and Chl $b$, plus $\beta \varepsilon$-Car and $\beta \beta$-Car (Fig. 2). Therefore, the FDSC technique was evaluated using these pigment pairs. Additionally, the Pras and Hex-kfuco pair co-eluted as a single peak in our UHPLC system, so their DHI-Qt standards were arbitrarily mixed. Although the $\mathrm{Chl} c_{1}$ and Chlide $a$ pair also co-eluted as a single peak (see the details in Sect. 3.5), the FDSC technique was solely used for the detection of $\mathrm{Chl} c_{1}$ with the maximum absorbance wavelength ( $\left.\lambda_{\max }\right)$ of Chlide $a$ in the UHPLC eluent (i.e., $431.54 \mathrm{~nm}$ ), because the authentic standard of $\mathrm{Chl} c_{1}$ was unavailable in this study. Consequently, the remaining four pairs ( $\mathrm{Chl} c_{2}$ and $\mathrm{MgDVP}$, Pras and Hex-kfuco, DVChl $b$ and Chl $b$, plus $\beta \varepsilon$-Car and $\beta \beta$-Car) were successfully resolved into each 
pigment component with the FDSC technique (Fig. 3). In Fig. 3a, the FDSCs at $440.40 \mathrm{~nm}$ and 447.09 $\mathrm{nm}$ indicate the elution profiles of $\mathrm{Chl} c_{2}$ and MgDVP, respectively. Similarly, the FDSCs at 448.84 $\mathrm{nm}$ and $458.85 \mathrm{~nm}$ represent the elution profiles of Pras and Hex-kfuco, respectively (Fig. 3b). Interestingly, a tiny peak derived from a degraded pigment, whose absorption spectrum differed from those of Pras and Hex-kfuco (data not shown), was detected at a retention time of ca. 2.91 min with the FDSC technique. In Fig. 3c, the FDSCs at $467.80 \mathrm{~nm}$ and $477.38 \mathrm{~nm}$ illustrate the elution profiles of DVChl $b$ and Chl $b$, respectively. Additionally, the FDSCs at $450.54 \mathrm{~nm}$ and $444.75 \mathrm{~nm}$ indicate the profiles of $\beta \varepsilon$-Car and $\beta \beta$-Car (Fig. 3d), respectively (Fig. 3c). In this study, the resolutions of Chl $c_{3}$ and MVChl $c_{3}$, diatoxanthin (Diato) and monadoxanthin (Monado), crocoxanthin (Croco) and Chl $b$ epimer (Chl $b^{\prime}$ ), plus $\mathrm{Chl} c_{2}$-monogalactosyldiacylglyceride (Chl $c_{2}$-MGDG) and DVChl $a$ pairs were also rather poor with $R_{\mathrm{s}}$ less than 1.0 (Table 3). However, most of the pigment standards were unavailable in this study (Table 3), so the FDSC technique was not tested on these pigment pairs.

The FDSC technique would be effective for the pigment pairs that were not completely or partially resolved, unless the two absorption spectra were identical to each other, the absorbance of one pigment at $\lambda_{\max }$ of the counterpart pigment was zero, and the co-eluted peak was significantly overlapped $\left(R_{\mathrm{S}}<1.0\right)$ with its neighboring peaks. On the basis of the FDSC technique, there must be only two pigments present to completely separate a co-eluted peak. In this study, $\varepsilon, \varepsilon$-carotene ( $\varepsilon \varepsilon$-Car), which can be found in pelagophytes (Jeffrey et al., 2011), co-eluted with $\beta \beta$-Car (Table 3 and Sect. 3.4). The co-occurrence of the three carotenes in a single peak hindered our ability to quantify each carotene using the FDSC technique. However, the occurrence of $\varepsilon \varepsilon$-Car and/or $\beta \beta$-Car could be estimated by obtaining the FDSC at $445.75 \mathrm{~nm}$, which was the $\lambda_{\max }$ of $\beta \varepsilon$-Car and yielded two (negative and positive) peaks with different retention times in the case that both $\varepsilon \varepsilon$-Car and $\beta \beta$-Car 
were present (as will be described later in Fig. 5b).

For the repeatability of the elution profiles obtained with the FDSC technique, the coefficient of variation (CV) values were determined for MgDVP and DVChl $b$ in the DHI-Mix standard $(n=3)$. As a result, the CV values of MgDVP and DVChl $b$ were $1.7 \%$ and $0.81 \%$, respectively. The results suggested that the FDSC technique was sufficiently quantitative. The coefficient of determination $\left(R^{2}\right)$ values for the calibration curves of Chl $c_{2}$, MgDVP, Pras, Hex-kfuco, DVChl $b$, Chl $b, \beta \varepsilon$-Car and $\beta \beta$-Car using the FDSC technique were $\geq 0.998$ ( $n \geq 5$ each case). The obtained calibration curves were applied to the data from phytoplankton cultures (Sect. 3.4) and field samples (Sect. 3.5). In the FDSC technique, LOQ values were of the order of $1.0 \mathrm{ng}$ for these pigments. As an alternative technique for the quantitation of pigment pairs co-eluted on chromatograms, the bichromatic equation method was proposed by Goericke and Repeta (1993) and Latasa et al. (1996). Compared to the bichromatic equation method, the major advantages of the FDSC technique are as follows: 1) poorly resolved peaks are visualized as elution profiles of each component on chromatograms, and 2) impurity peaks that are hidden in or by the target peak can be detected (Yanagisawa, 2014 and Fig. 3b).

\subsection{Separation and identification of pigments in phytoplankton cultures}

Chlorophylls and carotenoids in well-known marine phytoplankton species (Table 1) were also generally resolved well with our UHPLC system (Fig. 4). Some of the detected pigments were not involved in the pigment standards (Table 3) used in this study. In the case that $\beta \varepsilon$-Car and $\beta \beta$-Car co-existed in each phytoplankton culture, percent contributions of $\beta \varepsilon$-Car to the sum of $\beta \varepsilon$-Car and 
$\beta \beta$-Car were estimated in terms of weight using the FDSC technique, and the estimates were indicated on the chromatograms with peak number. Similarly, percent contributions of MgDVP to the sum of $\mathrm{Chl} c_{2}$ and MgDVP were calculated in the same manner, but the values obtained were consistently below $5 \%$.

For cyanobacteria, zeaxanthin (Zea; peak 23) and $\beta \beta$-Car (peak 38) were major carotenoids both in the Trichodesmium erythraeum (Figs. 4a) and Synechococcus sp. (Fig. 4b) strains. In previous studies, two types of cyanobacteria have been proposed in terms of pigment and morphological patterns (Jeffrey and Wright, 2006): type 1 comprising colonial forms and type 2 comprising coccoid forms, but lacking the minor carotenoids in type 1. The Tr. erythraeum and Synechococcus sp. strains are classified into type 1 and type 2, respectively. However, myxoxanthophyll (Myxo) and echinenone (Echin), which are specific to cyanobacteria type 1, were not confirmed in the Tr. erythraeum strain. These results agreed with those of Carpenter et al. (1993), who reported that Tr. erythraeum possessed little Myxo and Echin, whereas the other species $T r$. thiebautii possessed significant amounts of these carotenoids. In the Synechococcus strain, Chl $a$ allomer (i.e., Chl $a$ allo; peak 32) was detected, indicating the oxidation of Chl $a$ by cell senescence (Franklin et al., 2012).

The resolution between $\mathrm{Chl} c_{1}$ (peak 6) and $\mathrm{Chl} c_{2}$ (peak 4) was confirmed from the diatom Chaetoceros gracilis (Fig. 4c). Recently, Akimoto et al. (2014) reported on the presence of Chl $c_{1}$ and Chl $c_{2}$ and their photosynthetic functions in Ch. gracilis. The presence of Chlide $a$ (peak 7), a hydrolysis product of Chl $a$ by the enzyme chlorophyllase (Jeffrey and Hallegraeff, 1987), was hardly detected from the absorption spectrum at $675 \mathrm{~nm}$ (data not shown), whereas this pigment was observed in the Thalassiosira oceanica strain (Fig. $4 \mathrm{~d}$ ). The occurrence of Chl $c_{3}$ in the Th. oceanica 
strain (Vandenhecke et al., 2015) was also verified in this study (Fig. 4d). The pigment MgDVP was not detected in the diatom strains as estimated from the FDSC technique. The carotenoid compositions in the two diatom strains were the same as each other, and these were typical of most marine diatoms (Jeffrey et al., 2011). Using the Ch. gracilis strain as a representative culture, the repeatability of pigment data derived from triplicate filter samples was examined. As a result, the $\mathrm{CV}$ values of $\mathrm{Chl} a$ and the sum of major pigments (Chl $c_{2}, \mathrm{Chl} c_{1}$, Fuco, Diadino, $\mathrm{Chl} a$, and $\beta \beta$-Car) were $2.0 \%$ and $1.4 \%$, respectively. The obtained values corresponded to the state-of-the-art performance category defined by Hooker et al. (2012).

The dinoflagellate Heterocapsa triquetra showed a representative pigment pattern (Fig. 4e) of dinoflagellates containing Peri (peak 8) per Zapata et al. (2012). The pigment MgDVP was detected in the dinoflagellate strain using the FDSC technique. The peak that eluted at 0.84 min was interpreted as peridinol based on the earlier retention time and the absorption spectrum with the maximum at $477 \mathrm{~nm}$ in the eluent (Zapata et al., 2012).

The prasinophyte Tetraselmis sp. strain showed a unique pigment pattern among the strains examined in this study (Fig. 4f). The pigments 9'-cis-neoxanthin (c-Neo; peak 12), violaxanthin (Viola; peak 15), lutein (Lut; peak 24), and Chl $b$ (peak 28) were major accessory pigments in this strain. Interestingly, $c$-Neo co-eluted with an unknown pigment (presumably loroxanthin; Garrido et al., 2009) at the retention time of $2.68 \mathrm{~min}$ as estimated from the FDSC at the $\lambda_{\max }(436.55 \mathrm{~nm})$ of $c$-Neo in UHPLC eluent (data not shown). The pigments that eluted at 4.63 and 4.82 min were also unknown carotenoids and could be loroxanthin esters (Garrido et al., 2009). Although MgDVP is generally a major pigment in prasinophytes containing Pras (Latasa et al., 2004), MgDVP and Pras were not detected in this strain. Similar results were obtained from the Tetraselmis suecica ICMA 
(Zapata et al., 2000) and Tetraselmis sp. RCC500 strains (Latasa et al., 2004).

The pigment chromatograms for the haptophytes Emiliania huxleyi and Chrysochromulina camella are shown in Figs. 4g and 4h. According to Van Lenning et al. (2004), E. huxleyi possesses the following accessory pigments: $\mathrm{Chl} c_{3}$, MVChl $c_{3}$, Chl $c_{2}$, MgDVP, Fuco, Fuco-like pigment, Hex-kfuco, Hex-fuco, Diadino, Diato, unknown Chl $c_{2}$-monogalactosyldiacylglyceride (Chl $c_{2}$-MGDG) and $\beta \beta$-Car (and occasionally $\beta \varepsilon$-Car). The Chl $c_{2}$-MGDG of E. huxleyi was also identified as Chl $c_{2}$-MGDG [18:4/14:0] (Zapata et al., 2004). In this study, most of the pigments could be identified based on their authentic standards, and the presence of MgDVP was also confirmed by the FDSC technique. Although a MVChl $c_{3}$ standard was not available, the pigment was identified based on the retention time and absorption spectrum reported by Roy et al. (2011). The separation of MVChl $c_{3}$ from Chl $c_{3}$ with the UHPLC technique was rather incomplete $\left(R_{\mathrm{s}}=0.92\right.$; Table 3$)$. The Fuco-like pigment (Zapata et al., 2001), which possessed the same absorption spectrum as that of 19'-butanoyloxyfucoxanthin (But-fuco; Table 3) and could be 19'-pentanoyloxyfucoxanthin (Airs and Llewellyn, 2005), was detected at the retention time of $2.72 \mathrm{~min}$. The pigment composition of the haptophyte C. camella (Fig. 4h) was almost the same as that observed for E. huxleyi (Fig. 4g). However, Fuco and Hex-kfuco were more distinct for $C$. camella, which agreed well with Zapata et al. (2001).

For the pelagophyte Pelagococcus subviridis (Fig. 4i), But-fuco (peak 10) was the major carotenoid in this strain. This result agrees with those of Wright et al. (1991) and Zapata et al. (2000). As estimated from the FDSC technique, MgDVP was contained in this strain. Zapata et al. (2000) also observed a trace amount of MgDVP. It is known that $\varepsilon \varepsilon-C a r$ and $\beta \beta$-Car are present in this species (Wright et al., 1991; Zapata et al., 2000). Although the carotenes were co-eluted in our UHPLC system, 
the presence of $\varepsilon \varepsilon$-Car was confirmed by the absorption spectrum, in which a distinct peak at approximately $416 \mathrm{~nm}$ appeared (Table 3 ).

In the cryptophyte Rhodomonas lens (Fig. 4j), alloxanthin (Allo), which is specific for cryptophytes (Jeffrey et al., 2011), was the principal carotenoid (peak 20), which agrees with the report of Vaz et al. (2015). Although Monado (peak 22) and Croco (peak 29) were not contained in a set of our pigment standards (Table 3), these carotenoids were detected in this strain. The separations of Monado from Diato and of Croco from Chl $b$ ' were rather incomplete $\left(R_{\mathrm{s}}=0.88\right.$ and 0.83 , respectively) as mentioned above.

3.5 Separation and quantification of pigments from the tropical and subarctic Pacific and the neritic Bering Sea

A number of chlorophylls and carotenoids derived from phytoplankton assemblages were successively resolved with the UHPLC method, including the FDSC technique (Fig. 5). The algal pigments were identified, and the major pigments were further quantified (Appendix A). Then, the data from the duplicate samples were averaged.

The pigment chromatograms obtained from $5 \mathrm{~m}$ (Fig. 5a) and SCM (Fig. 5b) at stn. A in the central tropical North Pacific resembled those in the oligotrophic subtropical South Pacific as analyzed with HPLC (Ras et al., 2008) except in regards to retention time. The pigments DVChl $a$ and DVChl $b$, which are specific markers for the cyanobacterium Prochlorococcus (Chisholm et al., 1988), were only detected at stn A among the stations in this study. At the surface layer of stn. A, Zea (peak 23), which has an important role in the photo-protection of prokaryotic organisms (Mella-Flores et al, 
2012), was the principal accessory pigment, indicating the predominance of cyanobacteria. The contribution of DVChl $b$ to the sum of DVChl $b$ and Chl $b$ increased from $40 \%$ at the surface to $78 \%$ at the SCM layer as estimated from the FDSC technique. This increase indicates the relatively high abundance of low-light-adapted Prochlorococcus, which possesses more pcb genes encoding the DVChl a/b-binding antenna complexes than high-light-adapted Prochlorococcus (Bibby et al., 2003), among the total Chl $b$-related organisms (Prochlorococcus and eukaryotic green algae) at the SCM layer. The co-elution of DVChl $b$ and $\mathrm{Chl} b$ in a single peak could be a drawback if the contribution of eukaryotic green algae (prasinophytes, chlorophytes and euglenophytes) to the total Chl biomass must be evaluated in the presence of Prochlorococcus (Zapata et al., 2000). However, this issue has been resolved with the FDSC technique. A carotenoid (peak 31) was detected on the UHPLC pigment chromatograms (Figs. 5a and 5b), which could be $\alpha$-cryptoxanthin ( $\alpha$-Cryp; $\beta, \varepsilon$-carotene-3'-ol) or zeinoxanthin (Zeino; $\beta, \varepsilon$-carotene-3-ol), and their absorption spectra were identical to each other. This chromatographic peak has sometimes been reported from the studies conducted in tropical and subtropical open waters (e.g., Goericke and Repeta, 1993 and Ras et al., 2008) but was generally referred to as an unknown carotenoid. Recently, Takaichi et al. (2012) confirmed that a small amount of Zeino was contained in Prochlorococcus strains. Differentiation between $\alpha$-Cryp and Zeino is generally difficult because these pigments both have the same absorption spectra and chromatographic behavior (Meléndez-Martínez et al., 2004). Therefore, Meléndez-Martínez et al. (2004) identified Zeino by using mass spectrometry and a methylation test. Further investigation is needed for the identification of the carotenoid peak in our results. At the SCM layer, the cyanobacteria-derived pigments (Zea, DVChl $b$, and DVChl $a$ ), as well as But-fuco (peak 10) and Hex-fuco (peak 16) were major carotenoids, suggesting that pelagophytes and haptophytes also dominated the phytoplankton 
assemblages (also see Sect. 3.4). Relatively high contributions (34-39\%) of MgDVP to the sum of Chl $c_{2}$ and MgDVP were found both in the surface and SCM layers using the FDSC technique. Although MgDVP is an important intermediate of the Chl biosynthesis pathway in cyanobacteria and eukaryotic phytoplankton (Helfrich et al., 1999) and a major pigment in some prasinophytes (Latasa et al., 2004), MgDVP data were unavailable from the open subtropical and tropical Pacific partly due to difficulty in chromatographic separation between the two pigments.

The number of pigments detected at the surface layer of stn. B in the open subarctic Pacific (Fig 5c) was higher than those at stn. A (Fig. 5a), suggesting that the phytoplankton assemblages were composed of a wider variety of algal groups. The pigment pattern observed at stn. B was similar to that reported by Suzuki et al. (2002), who examined east-west differences in phytoplankton pigment composition in the subarctic Pacific during the summer of 1999, although Pras was not detected in this study. The carotenoid Hex-fuco (peak 16) was the most prominent accessory pigment in these studies, indicating the predominance of haptophytes in the subarctic Pacific during summer. Interestingly, the pigments detected in the haptophyte Emiliania huxleyi (Fig. 4g) were mostly observed at stn. B (Fig. 5c), suggesting the relatively high abundance of coccolithophores.

The pigment composition at stn. C in the neritic Bering Sea (Fig. 5d) was similar to that detected in the diatom strains (Figs. $4 \mathrm{c}$ and $4 \mathrm{~d}$ ). As estimated from the FDSC technique, $\beta \beta$-Car became the principal carotene at stn. $\mathrm{C}$ as well as stn. $\mathrm{B}$. Massive diatom blooms occur in the inner continental shelf and along the edge of the shelf region in the Bering Sea from spring to summer every year (Springer et al., 2007). Therefore, most of the pigments detected in this study were probably derived from diatoms. A relatively high level of Chlide $a$ (peak 7) was detected without any interference of Chl $c_{1}$ using the PDA detector at $675 \mathrm{~nm}$ (Fig. 6a), whereas the presence of Chlide $a$ 
was also obvious from the fluorescence detector (Fig. 6b). These results indicated that Chlide- $a$-containing senescent diatom cells (Jeffrey and Hallegraeff, 1987) were abundant at the station. Wright et al. (2010) and Suzuki et al. (2011) also showed that Chlide $a$ levels increased with the progress of diatom blooms, and the results were most likely due to increases in senescent diatoms.

\section{Conclusions}

We succeeded in shortening the analysis time for resolving the chlorophylls and carotenoids from marine phytoplankton with the UHPLC technique compared to the conventional HPLC method. The separation capability of our UHPLC technique was almost the same as that of the HPLC method. Additionally, the FDSC technique allowed us to resolve critical pigment pairs such as Chl $c_{2}$ and MgDVP, as well as DVChl $b$ and Chl $b$, although these pairs could not be separated in the UHPLC system at a single absorbance wavelength. The FDSC technique can be applied to the data derived from conventional HPLC systems with PDA detectors. The lower sample injection volume in the UHPLC technique could be a disadvantage when analyzing samples with low pigment concentration. However, this issue has been overcome by using the PDA detector with an $85 \mathrm{~mm}$ path length capillary cell and a fluorescence detector. In addition, the DMF bead-beating pigment extraction technique developed by Mock and Hoch (2005) was useful for reducing the volume of organic solvent to $1 \mathrm{~mL}$ in the case of $25 \mathrm{~mm} \mathrm{GF/F}$ filter samples versus $3 \mathrm{~mL}$ in sonication methods (Suzuki et al., 2002; Ras et al., 2008). Wright et al. (2010) slightly modified this bead-beating extraction method, and used $300 \mu \mathrm{L}$ of DMF plus $50 \mu \mathrm{L}$ of methanol containing an internal standard in 
the case of $13 \mathrm{~mm} \mathrm{GF/F}$ filter samples. However, it should be noted that DMF is more toxic than other solvents (e.g., methanol or acetone) commonly used for pigment extraction (Wright et al., 1997), so this organic solvent should be handled with care (e.g., used in a fume cupboard while wearing laboratory gloves). For field samples, an increase in the filtration volume of seawater can enhance the sensitivity of pigment detection, but a longer filtration period may compromise the shortening of the analysis time with the UHPLC technique.

Overall, our results indicate that the UHPLC technique can replace the conventional HPLC methods for pigment analysis and allow us to yield high-throughput data of the chlorophylls and carotenoids derived from marine phytoplankton. The UHPLC pigment analysis developed in this study can be used not only for marine phytoplankton, but also for other photosynthetic organisms such as macroalgae and terrestrial higher plants, because of their similar compositions of chlorophylls and carotenoids (Falkowski and Raven, 2007). At present, international inter-calibration exercises (SeaHARRE-7 and QUASIMEME) for phytoplankton pigment analysis are under way, and these calibration procedures can reduce uncertainties of the data obtained with the UHPLC technique. For example, ocean color satellite remote sensing requires high calibration accuracy, so that large numbers of reliable in situ pigment data are indispensable (Hooker et al., 2012). In terms of this point, our high-throughput UHPLC pigment analysis method would be promising for the future calibration and validation exercises of ocean color data from next-generation satellite sensors.

\section{Acknowledgements}


The present study was conducted as part of the project "Development of simulation techniques to nowcast the biodiversity of marine phytoplankton" in the CREST program "Establishment of core technology for the preservation of marine diversity and ecosystems" of the Japan Science and Technology Agency (JST). In addition, this study was partly supported by the GCOM-C1 RA 4 of Japan Aerospace Exploration Agency (JAXA), the Grant-in-Aid for Scientific Research on Innovative Areas (\#22681004), Scientific Research (S) (\#22221001) and the project "The study of Kuroshio ecosystem dynamics for sustainable management" from the Ministry of Education, Culture, Sports, Science and Technology (MEXT), Japan. We wish to thank Dr. H. Endo and Ms. N. Araki for their help in the field and laboratory. Prof. S. Taguchi and Dr. T. Fujiki are acknowledged for the NEPCC culture. We thank Prof. A. Tanaka for the DVChl $b$ standard. Two anonymous referees are also acknowledged for their constructive comments and helpful suggestions on the manuscript. 


\section{References}

Airs, R.L., Llewellyn, C.A., 2005. Improved detection and characterization of fucoxanthin-type carotenoids: novel pigments in Emiliania huxleyi (Prymnesiophyceae). J. Phycol. 42, 391-399.

Akimoto, S., Teshigahara, A., Yokono, M., Mimuro, M., Nagao, R., Tomo, T., 2014. Excitaiton relaxation dynamics and energy transfer in fucoxanthin-chlorophyll a/c-protein complexes, probed by time-resolved fluorescence. Biochim. Biophys. Acta 1837, 1514-1521.

Barlow, R.G., Cumming, D.G., Gibb, S.W., 1997. Improved resolution of mono- and divinyl chlorophylls $a$ and $b$ and zeaxanthin and lutein in phytoplankton extracts using reverse phase C-8 HPLC. Mar. Ecol. Prog. Ser. 161, 303-307.

Bibby, T.S., Mary, I., Nield, J., Partensky, F., Barber, J., 2003. Low-light-adapted Prochlorococcus species possess specific antennae for each photosystem. Nature 424, 1051-1054.

Bidigare, R.R., Van Heukelem, L., Trees, C.S., 2005. Analysis of algal pigments by high-performance liquid chromatography, in: R. A. Andersen (Ed.), Algal Culturing Techniques. Elsevier, Amsterdm, pp. 327-35.

Bittner, L., Gobet, A., Audic, S., Romac, S., Egge, E.S., Santin, S., Ogata, H., Probert, I., Edvardsen, B., De Vargas, C., 2013. Diversity patterns of uncultured haptophytes unravelled by pyrosequencing in Napes Bay, Mol. Ecol. 22, 87-101.

Cabooter, D., Desmet, G., 2012. General overview of fast and high-resolution approaches in liquid chromatography, in: Gullarme, D., Veuthey, J.-L. (Eds.), UHPLC in Life Sciences. RSC Publishing. Cambridge, pp. 1-28.

Carpenter, E., O’Neil, J.M., Dawson, R., Capone, D.G., Siddiqui, P.J.A., Roeneberg, T., Bergman, B., 
1993. The tropical diazotrophic phytoplankter Trichodesmium: biological characteristics of two common species. Mar. Ecol. Prog. Ser. 95, 295-304.

Chen, Y.-B., Zehr, J.P., Mellon, M., 1996. Growth and nitrogen fixation of the diazotrophic filamentous nonheterocystous cyanobacterium Trichodesmium sp. IMS 101 in defined media: evidence for a circadian rhythm. J. Phycol. 32, 916-923.

Chisholm, S.W., Olson, R.J., Zettler, E.R., Goericke, R., Waterbury, J.B., Welshmeyer, N.A., 1988. A novel free-living prochlorophyte abundant in the oceanic euphotic zone. Nature 334, 340-343.

Claustre, H., Hooker, S.B., Van Heukelem, L., Berthon, J.-F., Barlow, R., Ras, J., Sessions, H., Targa, C., Thomas, C.S., van der Linde, D., Marty, J.-C., 2004. An intercomparison of HPLC phytoplankton pigment methods using in situ samples: application to remote sensing and database activities. Mar. Chem. 85, 41-61.

Delwiche, C.F., 1999. Tracing the thread of plastid diversity through the tapestry of life. Amer. Nat. 154, S164-S177.

Falkowski, P.G., Raven, J.A., 2007. Aquatic Photosynthesis, second ed. Princeton University Press. Princeton.

Fountain, K.J., Neue, U.D., Grumbach, E.S., Diehl, D.M., 2009. Effects of extra-column band spreading, liquid chromatography system operating pressure, and column temperature on the performance of sub-2- $\mu \mathrm{m}$ porous particles. J. Chromatogr. A 1216, 5979-5988.

Fountain, K. J., Iraneta, P.C., 2012. Instrumentation and columns for UHPLC separations, in: Gullarme, D., Veuthey J.-L. (Eds.), UHPLC in Life Sciences. RSC Publishing, Cambridge, pp. 29-66.

Franklin, D.J., Airs, R.L., Fernandes, M., Bell, T.G., Bongaerts, R.J., Berges, J.A., Malin, G., 2012. 
Identification of senescence and death in Emiliania huxleyi and Thalassiosira pseudonana: Cell staining, chlorophyll alterations, and dimethylsulforniopropionate (DMSP) metabolism. Limnol. Oceanogr. 57, 305-317.

Fu, W., Magnúsdóttir, M., Brynjólfson, S., Palsson, B. Ø, Paglia, G., 2012. UPLC-UV-MS ${ }^{\mathrm{E}}$ analysis for quantification and identification of major carotenoid and chlorophyll species in algae. Anal. Bioanal. Chem. 404, 3145-3154.

Garrido, J.L., Rodríguez, F., Zapata, M., 2009. Occurrence of loroxanthin, loroxanthin descenoate, and loroxanthin dodecenoate in Tetraselsmis species (Prasinophyceae, Chlorophyta). J. Phycol. 45, 366-374.

Garrido, J.L., Airs, R.L., Rodríguez, F., Van Heukelem, L., Zapata, M., 2011. New HPLC separation techniques, in: Roy, S., Llewellyn, C.A., Egeland, E.S., Johsen, G. (Eds.), Phytoplankton Pigments: Characterization, Chemotaxonomy and Applications in Oceanography. Cambridge University Press, Cambridge, pp. 165-194.

Goericke, R., Repeta, D., 1993. Chlorophylls $a$ and $b$ and divinyl chlrorophylls $a$ and $b$ in the open subtropical North Atlantic Ocean. Mar. Ecol. Prog. Ser. 101, 307-313.

Goes, J.I., Handa, N., Taguchi, S., Hama, T., 1994. Effect of UV-B radiation on the fatty acid composition of the marine phytoplanktoer Tetraselmis sp.: relationship to cellular pigment. Mar. Ecol. Prog. Ser. 114, 259-274.

Gritti, F, Guiochon, G., 2008. Complete temperature profiles in ultra-high-pressure liquid chromatography columns. Anal. Chem. 80, 5009-5020.

Guillard, R.R.L., 1975. Culture of phytoplankton for feeding marine invertebrats, in: Smith, W.L., Chanley, M.H. (Eds.), Culture of Marine Invertebrate Animals. Plenum Press, New York, pp. 
26-60.

Guillard, R.R.L., Hargraves, P.E., 1993. Stichochrysis immobilis is a diatom, not a chrysophyte. Phycologia 32, 234-236.

Hackett, J.D., Yoon, H.S., Butterfield, N.J., Sanderson, M.J., Bhattacharya, D., 2007. Plastid endosymbiosis: sources and timing of the major events, In Falkowski, P.G., Knoll, A.H. (Eds.), Evolution of Primary Producers in the Sea. Elsevier, Amsterdam, pp. 109-132.

Hadziavdic, K., Lekang, K., Lanzen, A., Jonassen, I., Thompson, E.M., Troedsson, C., 2014. Characterization of the $18 \mathrm{~S}$ rRNA gene for designing universal eukaryote specific primers. PLOS ONE 9, e87624.

Helfrich, M., Ross, A., King, G.C., Turner, A.G., Larkum, W.D., 1999. Identification of [8-vinyl]-protochlorophyllide $a$ in phototrophic prokaryotes and algae: chemical and spectroscopic properties. Biochim. Biophys. Acta 1410, 262-272.

Hirata, T., Hardman-Mountfold, N.J., Brewin, R.J.W., Aiken, J., Barlow, J., Suzuki, K., Isada, T., Howell, E., Hashioka, T., Noguchi-Aita, M., Yamanaka, Y., 2011. Synoptic relationships between surface Chlorophyll-a and diagnostic pigments specific to phytoplankton functional types. Biogeosciences 8, 311-327.

Hooker, S.B., Clementson, L., Thomas, C.S., Schlüter, L., Allerup, M., Ras, J., Claustre, H., Normandeau, C., Cullen, J., Kienast, M., Kolowski, W., Vernet, M., Chakraborty, S., Lohrenz, S., Tuel, M., Redalje, D., Cartaxana, P., Mendes, C.R., Brotas, V., Matondkar, S.G.P., Parab, S.G., Neeley, A., Egeland, E.S., 2012. The fifth SeaWiFS HPLC Analysis Round-Robin Experiment (SeaHARRE-5), NASA Technical Memorandum 2012-217503. NASA Goddard Space Flight Center, Maryland. 
Jayaraman, S., Knuth, M., Cantwell, M., Santos, A., 2011. High performance liquid chromatographic analysis of phytoplankton pigments using a $\mathrm{C}_{16}$-Amide column, J. Chromatogr. A 1218, $3432-3438$.

Jeffrey, S.W., Hallegraeff, G.M., 1987. Chlorophyllase distribution in ten classes of phytoplankton: a problem for chlorophyll analysis. Mar. Ecol. Prog. Ser. 35, 293-304.

Jeffrey, S.W., Mantoura, R.F.C., Wright, S.W., 1997. Phytoplankton Pigments in Oceanography. UNESCO Publishing, Paris.

Jeffrey, S.W., Wright, S.W., 2006. Photosynthetic pigments in marine microalgae: Insights from cultures and the sea, in: D. V. Subba Rao (Ed.), Algal Cultures, Analogues of Blooms and Applications. Science Publishers, New Hampshire, pp. 33-90.

Jeffrey, S.W., Wright, S.W., Zapata, M., 2011. Microalgal classes and their signature pigments, in: Roy, S., Llewellyn, C.A., Egeland, E.S., Johsen, G. (Eds.), Phytoplankton Pigments: Characterization, Chemotaxonomy and Applications in Oceanography. Cambridge University Press, Cambridge, pp. $165-194$.

Latasa, M., Bidigare, R.R., Ondrusek, M.E., Kennicutt II, M.C., 1996. HPLC analysis of algal pigments: a comparison exercise among laboratories and recommendations for improved analytical performance. Mar. Chem. 51, 315-324.

Latasa, M., Scharek, R., Le Gall, F., Guillou, L., 2004. Pigment suits and taxonomic group in Prasinophyceae. J. Phycol. 40, 1149-1155.

Lestremau, F., Wu, D., Szücs, R., 2010. Evaluation of $1.0 \mathrm{~mm}$ i.d. column performance on ultra high pressure liquid chromatography instrumentation. J. Chromatogr. A 1217, 4925-4933.

López, M., Arce, L., Garrido, J., Ríos, A, Valcárcel, M., 2004. Selective extraction of astaxanthin from 
crustaceans by use of supercritical carbon dioxide. Talanta 64, 726-731.

Lu, S., Li, L., 2008. Carotenoid metabolism: Biosynthesis, regulation, and beyond. J. Integr. Plant Biol. $50,778-785$.

Mackey, D.M., Mackey, D.J., Higgins, H.W., Wright, S.W., 1996. CHEMTAX - a program for estimating class abundances from chemical markers: application to HPLC measurements of phytoplankton. Mar. Ecol. Prog. Ser. 144, 265-283.

MacNair, J.E., Lewis, K.C., Jorgenson, J.W., 1997. Ultrahigh-pressure reversed-phase liquid chromatography in packed capillary columns. Anal. Chem. 69, 983-989.

Mantoura, R.F.C., Wright, S.W., Jeffrey, S.W., Barlow, R.G., Cummings, D.E., 1997. Filtration and storage of pigments from microalgae, in: Jeffrey, S.W., Mantoura, R.F.C., Wright, S.W. (Eds.), Phytoplankton Pigments in Oceanography. UNESCO Publishing, Paris, pp. 283-305.

Meléndez-Martínez, A.J., Britton, G., Vicario, I.M., Heredia, F.J., 2004. Identification of zeinoxanthin in orange juices. J. Agric. Food Chem 53, 6362-6367.

Mella-Flores, D., Six, C., Ratin, M., Partensky, F., Boutte, C., Le Corguillé, G., Marie, D., Blot, N., Gourvil, P., Kolowrat, C., Garzcarek, L., 2012. Prochlorococcus and Synechococcus have evolved different adaptive mechanisms to cope with light and UV stress. Front. Microbiol. 3, Article 285, $1-20$.

Mock, T., Hoch, N., 2005. Long-term temperature acclimation of photosynthesis in steady-state cultures of the polar diatom Fragilariopsis cylindrus. Photosyn. Res. 85, 307-317.

Nagata, N., Tanaka, R., Satoh, S., Tanaka, A., 2005. Identification of a vinyl reductase gene for chlorophyll synthesis in Arabidopsis thaliana and implications for the evolution of Prochlorococcus species. Plant Cell 17, 233-240. 
Pacini, T., Fu, W., Gudmundsson, S., Chiaravalle, A.E., Chiaravalle, A.E., Brynjolfson, S., Palsson, B.O., Astarita, G., Paglia, G., 2015. Multidimensional analytical approach based on UHPLC-UV-Ion mobility-MS for the screening of natural pigments. Anal. Chem. 87, 2593-2599.

Porra, R.J., Thompson, W.A., Kriedemann, P.E., 1989. Determination of accurate excitation coefficients and simultaneous equations for assaying chlorophylls $a$ and $b$ extracted with four different solvents: verification of the concentration of chlorophyll standards by atomic absorption spectroscopy. Biochim. Biophys. Acta 975, 384-394.

Ras, J., Claustre, H., Uitz, J., 2008. Spatial variability of phytoplankton pigment distributions in the subtropical South Pacific Ocean: comparison between in situ and predicted data. Biogeosciences 5, 353-369.

Roy, S., Llewellyn, C.A., Egeland, E.S., Johnsen, G., 2011. Phytoplankton Pigments: Characterization, Chemotaxonomy and Applications in Oceanography. Cambridge University Press, Cambridge.

Sanz, N., Garcia-Blanco, A., Gavalás-Olea, A., Loures, P., Garrido, J.L., 2015. Phytoplankton pigment biomarkers: HPLC separation using a pentafluorophenyloctadecyl silica column. Meth. Ecol. Evol., doi: $10.1111 / 2041-210 X .12406$.

Savitzky, A., Golay, M.J.E., 1964. Smoothing and differentiation of data by simplified least squares procedures. Anal. Chem. 36, 1627-1639.

Snyder, L.R., Kirkland, J.J., 1979. Introduction to Modern Liquid Chromatography, $2^{\text {nd }}$ ed. Wiley, New York.

Springer, A.M., McRoy, C.P., Flint, M.V., 2007. The Bering Sea Green Belt: shelf-edge processes and ecosystem production. Fish. Oceanogr. 5, 205-223.

Stomp, M., Huisman, J., Stal, L.J., Matthijs, H.C.P., 2007. Colorful niches of phototrophic 
microorganisms shaped by vibrations of the water molecule. ISME J. 1, 271-282.

Suzuki, K., Minami, C., Liu, H., Saino, T., 2002. Temporal and spatial patterns of chemotaxonomic algal pigments in the subarctic Pacific and the Bering Sea during the early summer of 1999. Deep-Sea Res. II 49, 5685-5704.

Suzuki, K., Kuwata, A., Yoshie, N., Shibata, A., Kawanobe, K., Saito, H., 2011. Population dynamics of phytoplankton, heterotrophic bacteria, and viruses during the spring bloom in the western subarctic Pacific. Deep-Sea Res. I 58, 575-589.

Takaichi, S., Mochimaru, M., Uchida, H., Murakami, A., Hirose, E., Maoka, T., Tsuchiya, T., Mimuro M., 2012. Opposite chilarity of $\alpha$-carotene in unusual cyanobacteria with unique chlorophylls, Acaryochloris and Prochlorococcus. Plant Cell Physiol. 53, 1181-1888.

Tanaka, R., Tanaka, A., 2011. Chlorophyll cycle regulates the construction and destruction of the light-harvesting complexes. Biochim. Biophys. Acta 1807, 968-976.

Vandenhecke, J. M.-R., Bastedo, J., Cockshutt, A.M., Campbell, D.A., Huot, Y., 2014. Changes in the Rubisco to photosystem ratio dominates photoacclimiation across phytoplankton taxa. Photosyn. Res. 124, 275-291.

Van Heukelem, L., Thomas, C.S., 2001. Computer-assisted high-performance liquid chromatography method development with applications to the isolation and analysis of phytoplankton pigments. J. Chromatogr. A 910, 31-49.

Van Heukelem, L., Hooker, S.B., 2011. The importance of quality assurance plan for method validation and minimizing undertainties in the HPLC analysis of phytoplankton pigments, in: Roy, S., Llewellyn, C.A., Egeland, E.S., Johsen, G. (Eds.), Phytoplankton Pigments: Characterization, Chemotaxonomy and Applications in Oceanography. Cambridge University Press, Cambridge, pp. 
195-242.

Van Lenning, K., Probert, I., Latasa, M., Estrada, M., Young, J.R., 2004. Pigment diversity of coccolithophores in relation to taxonomy, phylogeny and ecological preferences, in: Thierstein, H.R., Young, J.R. (Eds.), Coccolithophores: From Molecular Processes to Global Impact. Springer, Berlin, pp. 51-73.

Vaz, B., Fontan, N., Castiñeira, M., Álvarez, R., de Lera, Á.R., 2015. Synthesis of labile all-trans-7,8,7',8'-bis-acetylenic carotenoids by bi-directional Horner-Wadsworth-Emmons condensation. Org. Biomol. Chem. 13, 3024-3031.

Wright, S.W., Jeffrey, S.W., Mantoura, R.F.C., Llewellyn, C.A., Bjørnland, T., Repeta, D., Welshmeyer, N.A., 1991. Improved HPLC method for the analysis of chlorophylls and carotenoids from marine phytoplankton. Mar. Ecol. Prog. Ser. 77, 183-196.

Wright, S.W., 1997. Summary of terms and equations used to evaluate HPLC chromatograms, in: Jeffrey, S.W., Mantoura, R.F.C., Wright, S.W. (Eds.), Phytoplankton Pigments in Oceanography. UNESCO Publishing, Paris, pp. 622-630.

Wright, S.W., Jeffrey, S.W., Mantoura, R.F.C., 1997. Evaluation of methods and solvents for pigment extraction, in: Jeffrey, S.W., Mantoura, R.F.C., Wright, S.W. (Eds.), Phytoplankton Pigments in Oceanography. UNESCO Publishing, Paris, pp. 261-282.

Wright, S.W., van den Enden, R.L., Pearce, I., Davidson, A.T., Scott, F.J., Westwood, K.J., 2010. Phytoplankton community structure and stocks in the Southern Ocean $\left(30-80^{\circ} \mathrm{E}\right)$ determined by CHEMTAX analysis of HPLC pigment signatures. Deep-Sea Res. Pt. II 57, 758-778.

Yamamoto, A., Matsunaga, A., Ohto, M., Mizukami, E., Hayakawa, K., Miyazaki, M., 1995. Real-time analysis of multicomponent chromatograms: application to high-performance liquid 
chromatography. Analyst 120, 377-380.

Yanagisawa, T., 2014. Principle and summary of i-PDeA (Intelligent Peak Deconvolution Analysis). Shimadzu J. 2, 39-42.

Zapata, M., Rodríguez, F., Garrido, J.L., 2000. Separation of chlorophylls and carotenoids from marine phytoplankton: a new HPLC method using a reversed phase $\mathrm{C}_{8}$ column and pyridine-containing mobile phases. Mar. Ecol. Prog. Ser. 19, 59-45.

Zapata, M., Edvardsen, B., Rodríguez, F., Maestro, M. A., Garrido, J.L., 2001. Chlorophyll $c_{2}$ monogalactosyldiacylglyceride ester ( $\mathrm{chl} c_{2}$-MGDG). A novel marker pigment chrysochromulina species (Haptophyta). Mar. Ecol. Prog. Ser. 219, 85-98.

Zapata, M., Jeffrey, S.W., Wright, S.W., Rodríguez, F., Garrido, J.L., Clementson, L., 2004. Photosynthetic pigments in 37 species (65 strains) of Haptophyta: implications for oceanography and chemotaxonomy. Mar. Ecol. Prog. Ser. 270, 83-102.

Zapata, M., Fraga, S., Rodríguez, F., Garrido, J.L., 2012. Pigment-based chloroplast types in dinoflagellates. Mar. Ecol. Prog. Ser. 465, 33-52. 


\section{Figure captions}

Fig. 1. Sampling stations in the tropical (stn. A: $15^{\circ} 01^{\prime} \mathrm{N}, 170^{\circ} 02^{\prime} \mathrm{W}$ ) and subarctic (stn. B: $45^{\circ} 03^{\prime} \mathrm{N}$, $173^{\circ} 04^{\prime}$ W) North Pacific Ocean and the neritic Bering Sea (stn. C: $64^{\circ} 15^{\prime} \mathrm{N}, 168^{\circ} 00^{\prime} \mathrm{W}$ ) during July 8-29, 2014.

Fig. 2. Resolution of chlorophylls and carotenoids in the DHI-Mix standard (Lot mix-115) using the (a) HPLC with the SPD-M20A PDA detector (10 mm path length), (b) UHPLC with the SPD-M20A PDA detector (5 mm path length), and (c) UHPLC with the SPD-M30A PDA detector (85 mm path length) systems. Peaks are identified following the manufacturer's certificate and their numbers correspond to those in Table 3.

Fig. 3. The first derivative spectrum chromatograms (FDSCs) of (a) chlorophyll $c_{2}\left(\mathrm{Chl} c_{2}\right.$ ) and $\mathrm{Mg} 2,4$ divinyl pheoporphyrin $a_{5}$ monomethyl ester (MgDVP), (b) prasinoxanthin (Pras) and 19'-hexanoyloxy-4-ketofucoxanthin (Hex-kfuco), (c) divinyl chlorophyll $b$ (DVChl $b$ ) and chlorophyll $b(\mathrm{Chl} b)$, and (d) $\beta, \varepsilon$-carotene ( $\beta \varepsilon$-Car) and $\beta, \beta$-carotene ( $\beta \beta$-Car) pairs. Their absorbance chromatograms at appropriate wavelengths (the mean of $\lambda_{\max }$ values) are also shown in each figure.

Fig. 4. Separation of chlorophylls and carotenoids from (a) Trichodesmium erythraeum CCMP 1985, (b) Synechococcus sp. CCMP 1334, (c) Chaetoceros gracilis NEPCC645, (d) Thalassiosira oceanica CCMP1005, (e) Heterocapsa triquetra CCMP449, (f) Tetraselmis sp., (g) Emiliania huxleyi CCMP 1742, (h) Chrysochromulina camella CCMP289, (i) Pelagococcus subviridis CCMP1429, and (j) 
Rhodomonas lens CCMP739 strains using the UHPLC system with SPD-M30A PDA detector. Peak numbers correspond to those in Table 3. For carotenes except for those of (i) P. subviridis, the contributions (\%) of $\beta \varepsilon$-Car to the sum of $\beta \varepsilon$-Car and $\beta \beta$-Car in terms of weight were estimated with the FDSC technique, and the obtained results are indicated on the chromatograms with pigment numbers.

Fig. 5. Resolution of chlorophylls and carotenoids from (a) $5 \mathrm{~m}$ and (b) the SCM layer at $136 \mathrm{~m}$ at stn. A, (c) $5 \mathrm{~m}$ at stn. B, and (c) $5 \mathrm{~m}$ at stn. C. Peak numbers correspond to those in Table 3. Small panels represent the FDSCs, in which the scales of $\mathrm{x}$ - and y-axes were arbitrarily set, to resolve the Chl $c_{2}$ and MgDVP, DVChl $b$ and Chl $b$, or $\beta \varepsilon$-Car and $\beta \beta$-Car pairs as those in Fig. 3.

Fig. 6. Separation of chlorophylls and their derivatives at $5 \mathrm{~m}$ of stn. C using the UHPLC system with (a) SPD-M30A PDA detector at the absorbance of $675 \mathrm{~nm}$ and (b) fluorescence detector. Peak numbers correspond to those in Table 3. 
Table 1

Marine phytoplankton strains, culture media and incubation temperatures.

\begin{tabular}{l} 
Strains \\
\hline Cyanobacterla \\
Trichodesmium
\end{tabular}

Trichodesmium erythraeum CCMP1985

Synechococcus sp. CCMP1334

YBC-II

$24^{\circ} \mathrm{C}$

$f / 2$

$20^{\circ} \mathrm{C}$

\section{Dlatoms}

Chaetoceros gracilis NEPCC645

$f / 2$

$20^{\circ} \mathrm{C}$

Thalassiosira oceanica CCMP1005

$f / 2$

$20^{\circ} \mathrm{C}$

\section{Dinofiagellate}

Heterocapsa triquetra CCMP449

$f / 2$

$10^{\circ} \mathrm{C}$

\section{Prasinophyto}

Tetraselmis sp. **

$f / 2$

$20^{\circ} \mathrm{C}$

\section{Haptophytes}

Emiliania huxleyi CCMP1742

$f / 2$

$10^{\circ} \mathrm{C}$

Chrysochromulina camella CCMP289

L1-Si

$20^{\circ} \mathrm{C}$

\section{Pelagophyte}

Pelagococcus subviridis CCMP1429

L1-Si

$10^{\circ} \mathrm{C}$

\section{Cryptophyto}

Rhodomonas lens CCMP739

L1-Si

$20^{\circ} \mathrm{C}$

*YBC-II (Chen et al., 1996), f/2 (Guillard, 1975), and L1 -Si (Gullard and Hargraves, 1993).

**The strain was obtained from the culture collection at the Hokkaido National Fisheries Institute, Japan (Goes et al., 1994). 
Table 2

The sample injector program used in the UHPLC method.

\begin{tabular}{llll}
\hline Step & Source & Volume $(\mu \mathrm{L})$ & Speed $\left(\mu \mathrm{L} \mathrm{s}^{-1}\right)$ \\
\hline 1 Needle rinse & Methanol & - & - \\
2 Draw & Sample & 8 & 5 \\
3 Draw & Air & 0.1 & 5 \\
4 Needle rinse & Methanol & - & - \\
5 Draw & 28mM TBAA & 8 & 5 \\
6 Draw & Air & 0.1 & 5 \\
7 Needle rinse & Methanol & - & - \\
8 Draw & Sample & 8 & 5 \\
9 Draw & Air & 0.1 & 5 \\
10 Needle rinse & Methanol & - & - \\
11 Draw & 28mM TBAA & 8 & 5 \\
12 Draw & Air & 0.1 & 5 \\
13 Needle rinse & Methanol & - & - \\
14 Draw & Sample & 8 & 5 \\
15 Draw & Air & 0.1 & 5 \\
16 Needle rinse & Methanol & - & - \\
17 Draw & 28mM TBAA & 8 & 5 \\
18 Inject & Sample + 28 mM TBAA + Air & 48.5 (net 48) & 1 \\
\hline
\end{tabular}


Table 3

Marine phytoplankton pigments and their identification sources, PDA retention time, resolution $\left(R_{\mathrm{s}}\right)$ and maximum wavelength $\left(\lambda_{\max }\right)$ values as determined with the UHPLC or HPLC techniques.

\begin{tabular}{|c|c|c|c|c|c|c|c|c|}
\hline \multirow{2}{*}{ Peak No. } & \multirow{2}{*}{ Pigment } & \multirow{2}{*}{ Abbreviation } & \multirow[t]{2}{*}{ Identificaction source* } & \multicolumn{2}{|c|}{ PDA retention time $(\mathrm{min})$} & \multicolumn{2}{|c|}{$R_{\mathrm{s}}($ peak No./peak No.)** } & \multirow{2}{*}{$\begin{array}{l}\lambda_{\max }(\mathrm{nm}) \text { in } \\
\text { UHPLC eluent }\end{array}$} \\
\hline & & & & UHPLC & HPLC & UHPLC & HPLC & \\
\hline 1 & Chlorophyll $c_{3}$ & $\mathrm{Chl} c_{3}$ & DHI-Mix, DHI-Qt, D, G, H, I & 0.69 & 4.0 & & & 456,587 \\
\hline 2 & Monovinyl chlorophyll $c_{3}$ & $\mathrm{MVChl} c_{3}$ & G & 0.74 & 4.3 & $0.92(1 / 2)$ & $1.4(1 / 2)$ & 446,582 \\
\hline 3 & Peridinol & Periol & $\mathrm{E}$ & 0.84 & 5.2 & & & 476 \\
\hline 4 & Chlorophyll $c_{2}$ & $\mathrm{Chl} c_{2}$ & DHI-Mix, DHI-Qt, C, D, E, G, H, I, J & 1.05 & 6.2 & & & $447,583,634$ \\
\hline 5 & Mg 2,4 divinyl pheoporphyrin $a_{5}$ monomethyl ester & MgDVP & DHI-Mix, DHI-Qt, E, G, H, I & 1.07 & 6.2 & NR (4/5) & NR (4/5) & $440,578,631$ \\
\hline 6 & Chlorophll $c_{1}$ & $\mathrm{Chl} c_{1}$ & $\mathrm{C}, \mathrm{E}$ & 1.12 & 6.6 & $1.4(5 / 6)$ & & $442,582,634$ \\
\hline 7 & Chlorophyllide $a$ & Chlide $a$ & DHI-Qt, D & 1.14 & 6.7 & $N R(6 / 7)$ & NR $(6 / 7)$ & $432,621,667$ \\
\hline 8 & Peridinin & Peri & DHI-Mix, DHI-Qt, E & 1.78 & 10.6 & & & 475 \\
\hline 10 & 19'-Butanoyloxyfucoxanthin & But-fuco & DHI-Mix, DHI-Qt, G, I & 2.50 & 13.7 & & & 448,467 \\
\hline 11 & Fucoxanthin & Fuco & DHI-Mix, DHI-Qt, C, D, G, H, I & 2.56 & 14.0 & $1.3(10 / 11)$ & & 453 \\
\hline 12 & 9'-cis-Neoxanthin & $c-\mathrm{Neo}$ & DHI-Mix, DHI-Qt, F & 2.68 & 14.6 & & & $413,437,465$ \\
\hline 13 & Prasinoxanthin & Pras & DHI-Mix, DHI-Qt & 2.83 & 15.1 & & & 459 \\
\hline 14 & 19'-Hexanoyloxy-4-ketofucoxanthin & Hex-kfuco & DHI-Qt, G, H & 2.85 & 15.1 & $N R(13 / 14)$ & $N R(13 / 14)$ & 449,467 \\
\hline 15 & Violaxanthin & Viola & DHI-Mix, DHI-Qt, F & 2.89 & 15.4 & $1.4(14 / 15)$ & $1.4(14 / 15)$ & $416,440,469$ \\
\hline 16 & 19'-Hexanoyloxyfucoxanthin & Hex-fuco & DHI-Mix, DHI-Qt, G, H & 2.96 & 15.6 & $1.3(15 / 16)$ & $1.1(15 / 16)$ & 448,467 \\
\hline 17 & Astaxanthin & Asta & DHI-Mix & 3.01 & 15.9 & $1.0(16 / 17)$ & & 482 \\
\hline 18 & Diadinoxanthin & Diadino & DHI-Mix, DHI-Qt, C, D, E, G, H, I, J & 3.23 & 16.4 & & & 446,475 \\
\hline 19 & Dinoxanthin & Dino & DHI-Mix, E & 3.29 & 16.5 & $1.2(18 / 19)$ & $0.59(18 / 19)$ & $417,441,470$ \\
\hline 22 & Monadoxanthin & Monado & $\mathrm{J}$ & 3.75 & 18.6 & $0.88(21 / 22)$ & $0.63(21 / 22)$ & 446,474 \\
\hline 23 & Zeaxanthin & Zea & DHI-Mix, DHI-Qt, A, B & 3.88 & 19.1 & & & 451,477 \\
\hline 24 & Lutein & Lut & DHI-Mix, Sigma-Aldrich, F & 3.93 & 19.2 & $1.1(23 / 24)$ & $0.96(23 / 24)$ & 445,472 \\
\hline 25 & Dihydrolutein & Dhlut & DHI-Mix & 4.03 & 19.6 & & & 426,452 \\
\hline 26 & Trans- $\beta$-apo- 8 ' -carotenal (internal standard) & Apo & Sigma-Aldrich & 4.23 & 20.6 & & & 466 \\
\hline 27 & Divinyl chlorophyll $b$ & DVChl $b$ & DHI-Mix, K & 5.06 & 23.1 & & & $477,606,656$ \\
\hline 28 & Chlorophyll $b$ & Chl $b$ & DHI-Mix, Sigma-Aldrich, F & 5.09 & 23.1 & NR $(27 / 28)$ & NR $(27 / 28)$ & $468,602,650$ \\
\hline 29 & Crocoxanthin & Croco & $\mathrm{J}$ & 5.14 & 23.3 & & & 446,474 \\
\hline 30 & Chlorophyll $b$ epimer & Chl $b^{\prime}$ & Sigma-Aldrich & 5.18 & 23.5 & $0.83(29 / 30)$ & NR $(29 / 30)$ & $468,604,650$ \\
\hline 31 & $\alpha$-cryptoxanthin (zeinoxanthin? in Fig. 5) & $\alpha$-Cryp & DHI-Qt & 5.30 & 24.1 & & & 445,472 \\
\hline 32 & Chlorophyll $a$ allomer & Chl $a$ allo & $\mathrm{B}, \mathrm{H}$ & 5.43 & 24.4 & & & $430,620,665$ \\
\hline 33 & Chlorophyll $c_{2}$-monogalactosyldiacylglyceride & $\mathrm{Chl} \mathrm{c_{2 } - M G D G}$ & $\mathrm{G}, \mathrm{H}$ & 5.49 & 24.6 & $1.4(32 / 33)$ & $1.0(32 / 33)$ & $459,587,641$ \\
\hline 34 & Divinyl chlorophyll a & DVChl a & DHI-Mix, DHI-Qt & 5.55 & 24.8 & $0.45(33 / 34)$ & $0.78(33 / 34)$ & $442,620,666$ \\
\hline 35 & Chlorophyll a & Chl a & DHI-Mix, Sigma-Aldrich, A, B, C, D, E, F, G, H, I, J & 5.60 & 25.0 & $1.2(34 / 35)$ & $1.2(34 / 35)$ & $431,619,665$ \\
\hline 36 & Chlorophyll a epimer & $\mathrm{Chl} a^{\prime}$ & Sigma-Aldrich & 5.71 & 25.3 & & & $430,621,666$ \\
\hline 37 & $\varepsilon, \varepsilon$-carotene & $\varepsilon \varepsilon$-Car & 1 & 6.29 & 27.5 & & & $416,441,467$ \\
\hline 38 & $\beta, \varepsilon$-carotene & $\beta \varepsilon$-Car & DHI-Mix, Sigma-Aldrich, B, F, J & 6.30 & 27.6 & NR $(37 / 38)$ & $0.78(37 / 38)$ & 445,472 \\
\hline 39 & $\beta, \beta$-carotene & $\beta \beta$-Car & DHI-Mix, Sigma-Aldrich, A, B, C, D, E, F, G, H, I & 6.31 & 27.6 & NR $(38 / 39)$ & NR (38/39) & 451,475 \\
\hline
\end{tabular}

*DHI-Mix: DHI standard of mixed phytoplankton pigments, DHI-Qt: DHI quantitative standard; A: Trichodesmium erythraeum CCMP1985; B: Synechococcus sp. CCMP1334; C: Chaetoceros gracilis NEPCC645; D: Thalassiosira oceanica CCMP1005; E: Heterocapsa triquetra CCMP449; F: Tetraselmis sp.; G: Emiliania huxleyi CCMP1742; H: Chrysochromulina camella CCMP289; I: Pelagococcus subviridis CCMP1429;

J: Rhodomonas lens CCMP739, K: a dvr mutant of Arabidopsis thaliana.

** Values of $R_{s}<0.15$ are indicated, whereas blanks represent $R_{s} \geq 0.15$. NR: Not resloved. 
Table 4

PDA detector settings of center wavelength $\left(\lambda_{c}\right)$ and bandwidths $(\Delta \lambda)$ and values for the limit of quantification (LOQ) in this study and from four laboratories H, J, L and M in Claustre et al. (2004).

\begin{tabular}{|c|c|c|c|c|c|c|c|c|}
\hline Pigment & & UHPLC-SPD-M30A & UHPLC-SPD-M20A & HPLC-SPD-M20A & Lab H & Lab J & Lab L & Lab M \\
\hline \multirow[t]{2}{*}{ Chl a } & $\lambda_{\mathrm{c}} \pm \Delta \lambda(\mathrm{nm})$ & $436 \pm 4$ & $436 \pm 4$ & $436 \pm 4$ & $665 \pm 10$ & $436 \pm 4$ & $667 \pm 15$ & $440 \pm 7$ \\
\hline & LOQ (ng) & 0.2 & 1.6 & 0.8 & 0.5 & 0.5 & 0.3 & 1.2 \\
\hline \multirow[t]{2}{*}{ Fuco } & $\lambda_{\mathrm{c}} \pm \Delta \lambda(\mathrm{nm})$ & $436 \pm 4$ & $436 \pm 4$ & $436 \pm 4$ & $450 \pm 10$ & $436 \pm 4$ & $440 \pm 15$ & $440 \pm 7$ \\
\hline & LOQ (ng) & 0.1 & 0.9 & 0.6 & 0.6 & 0.4 & 0.3 & 0.5 \\
\hline
\end{tabular}




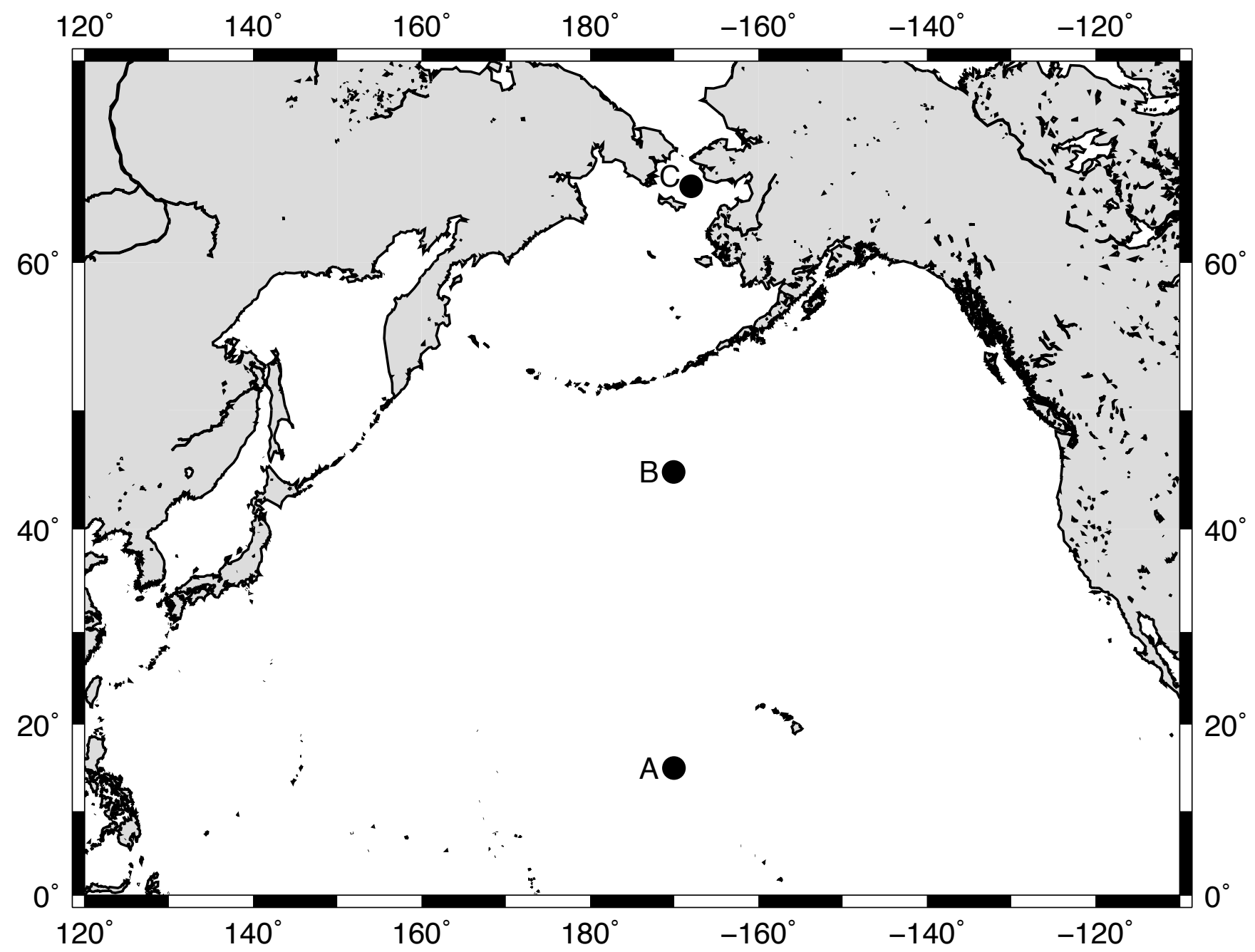

Fig. 1 

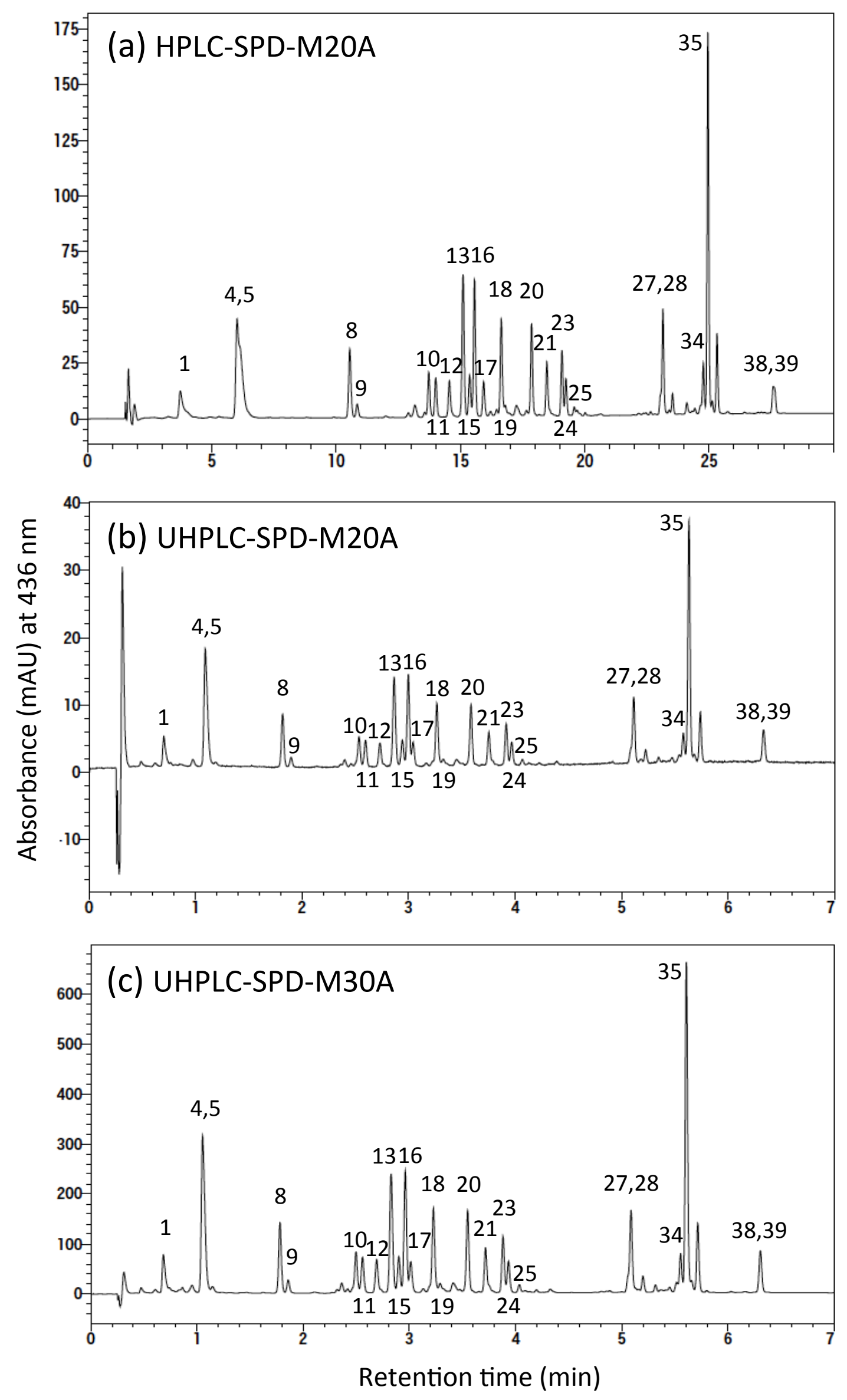

Fig. 2 


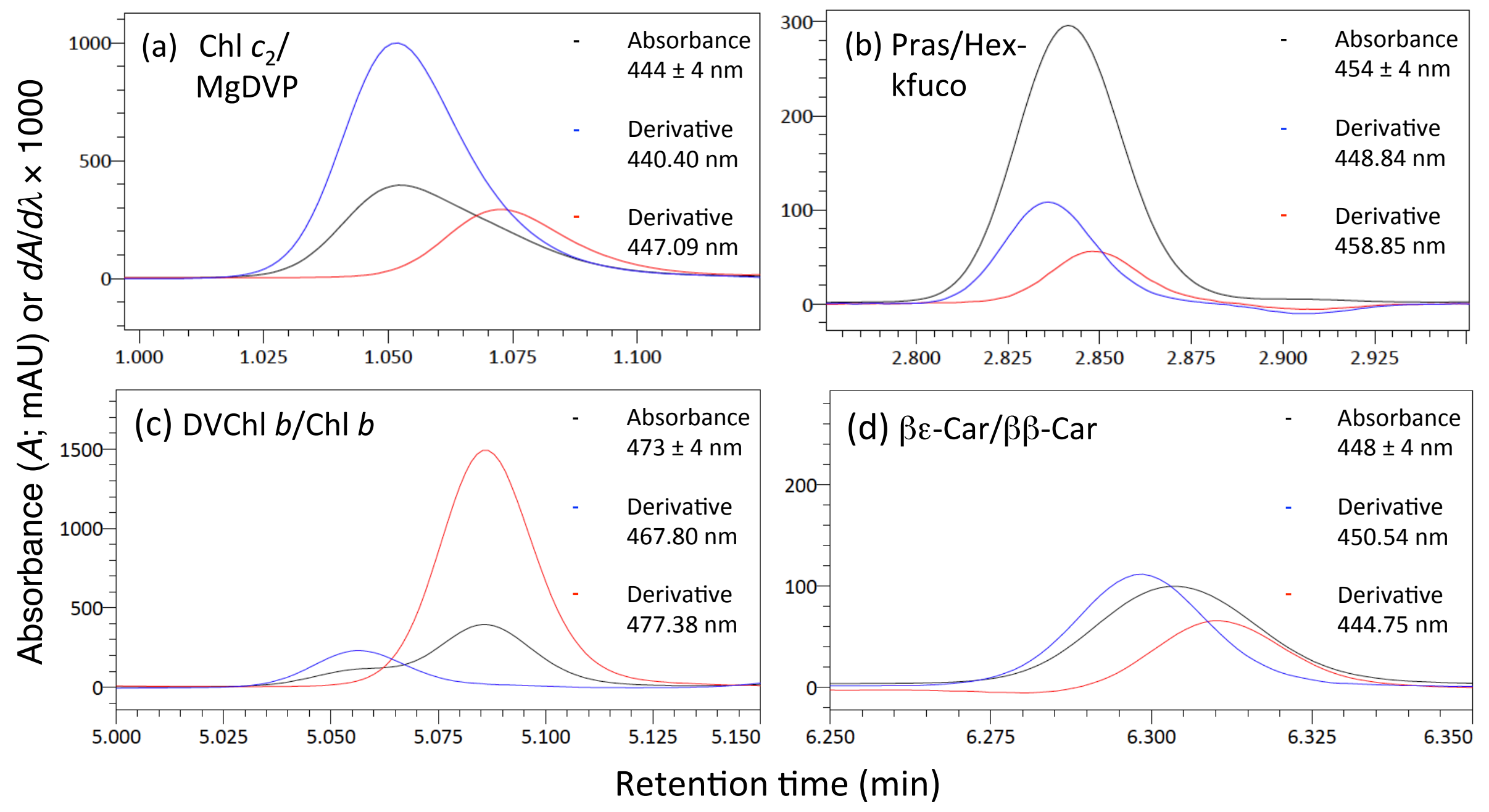

Fig. 3 


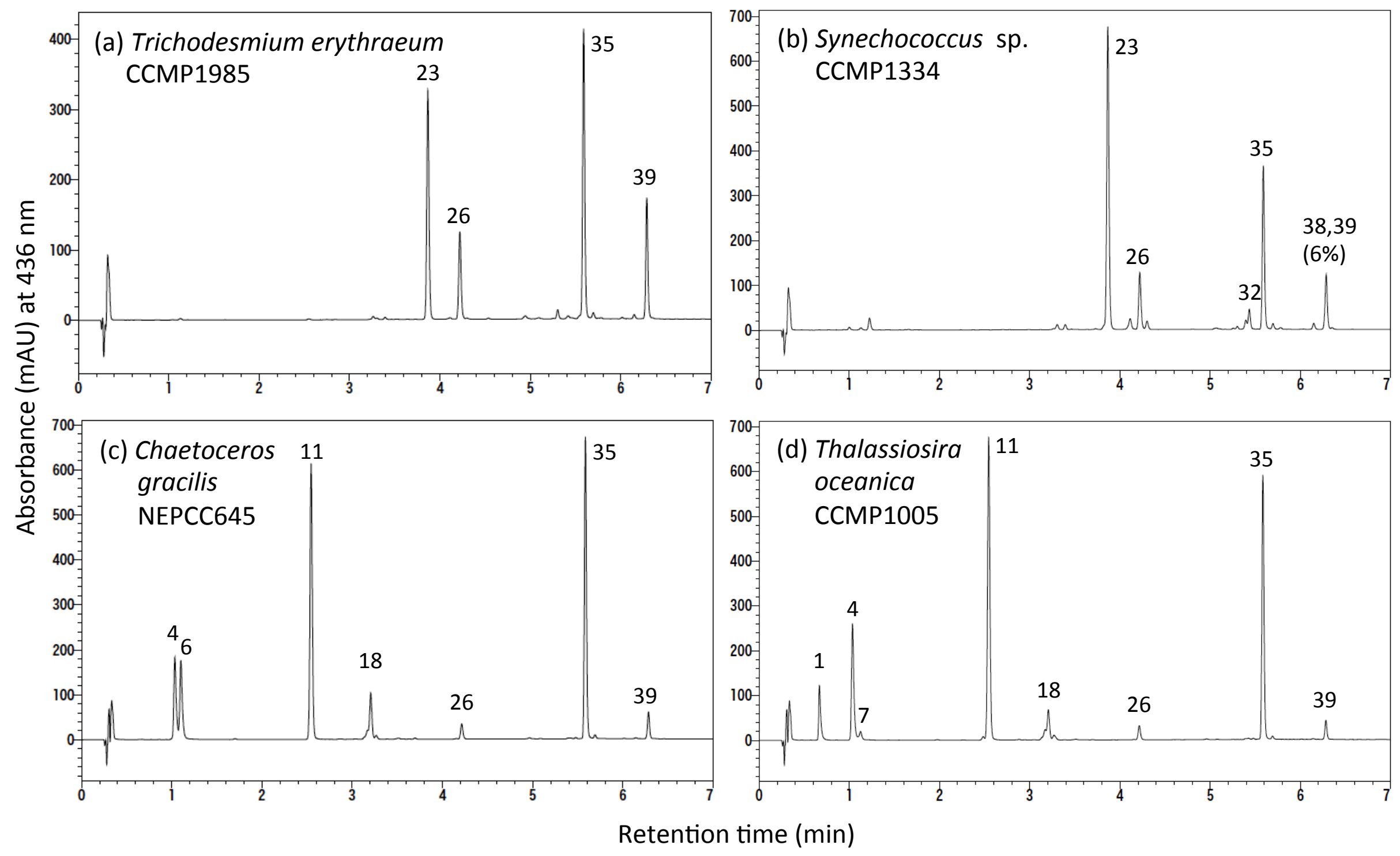

Fig. 4 


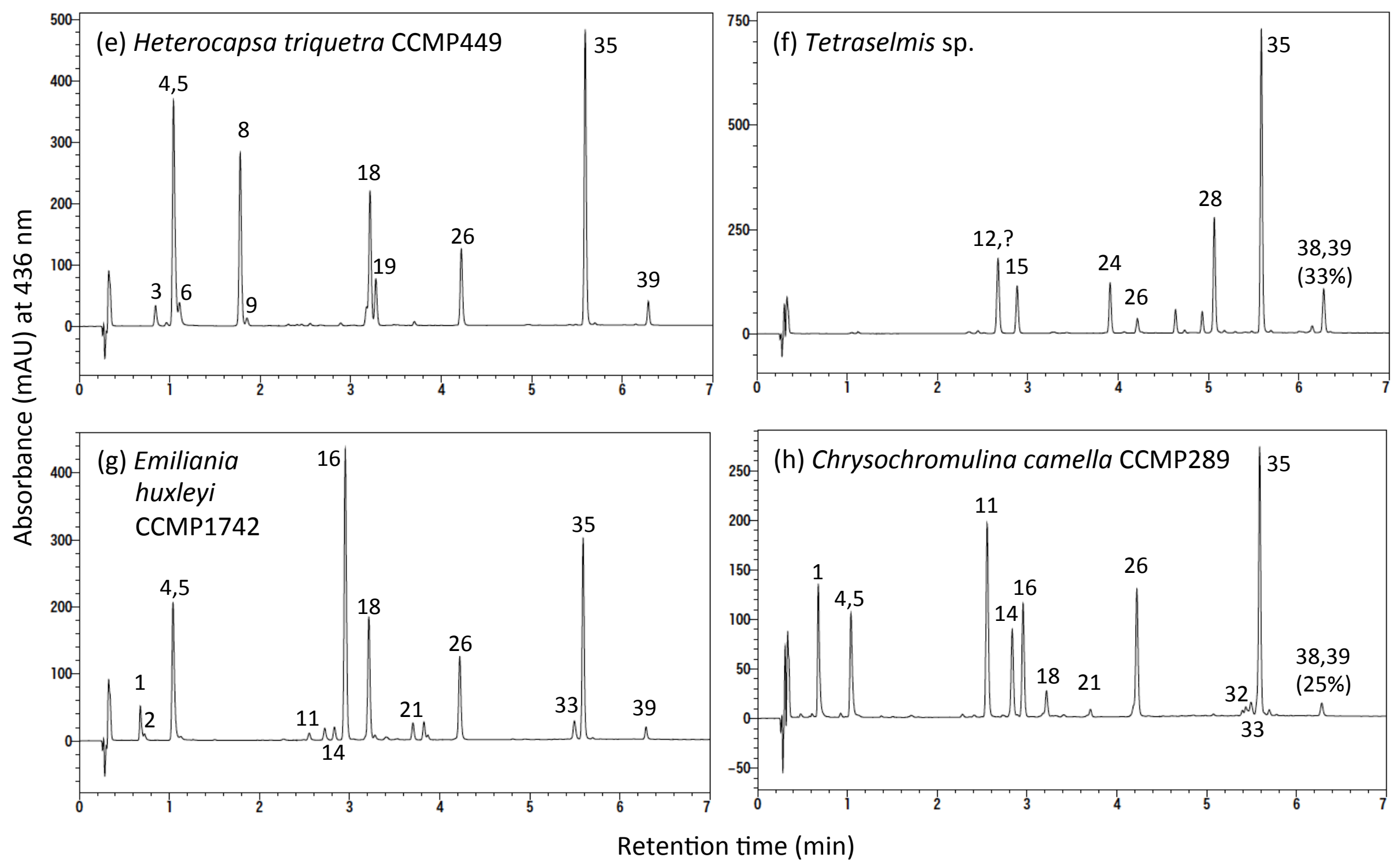

Fig. 4 (continued) 


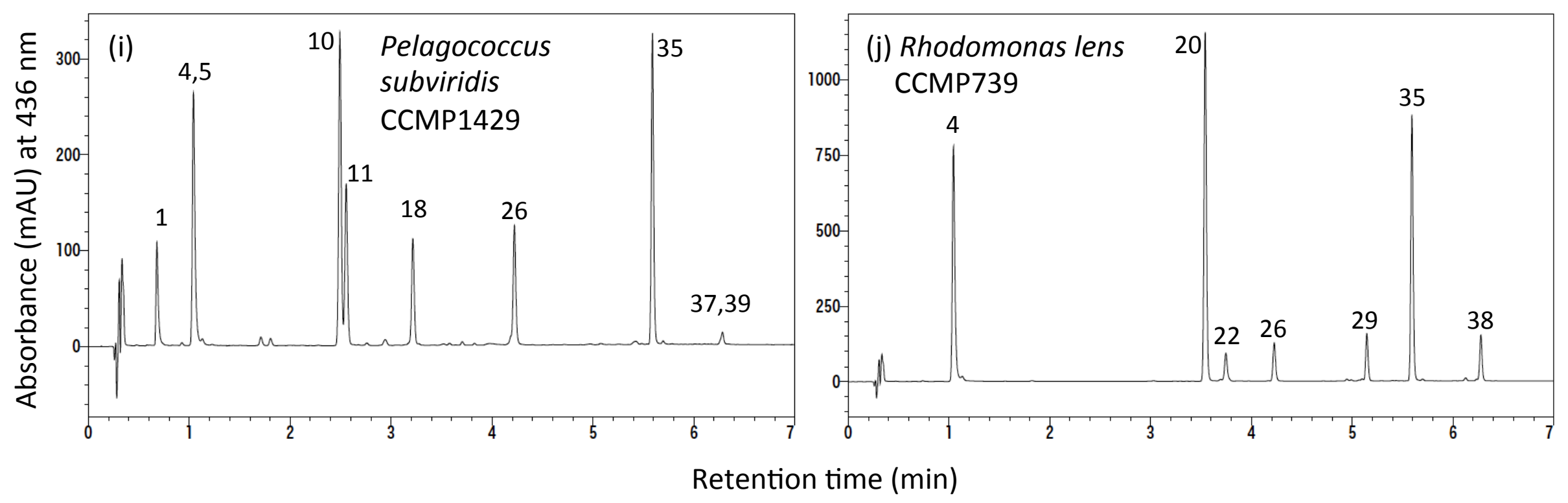

Fig. 4 (continued) 

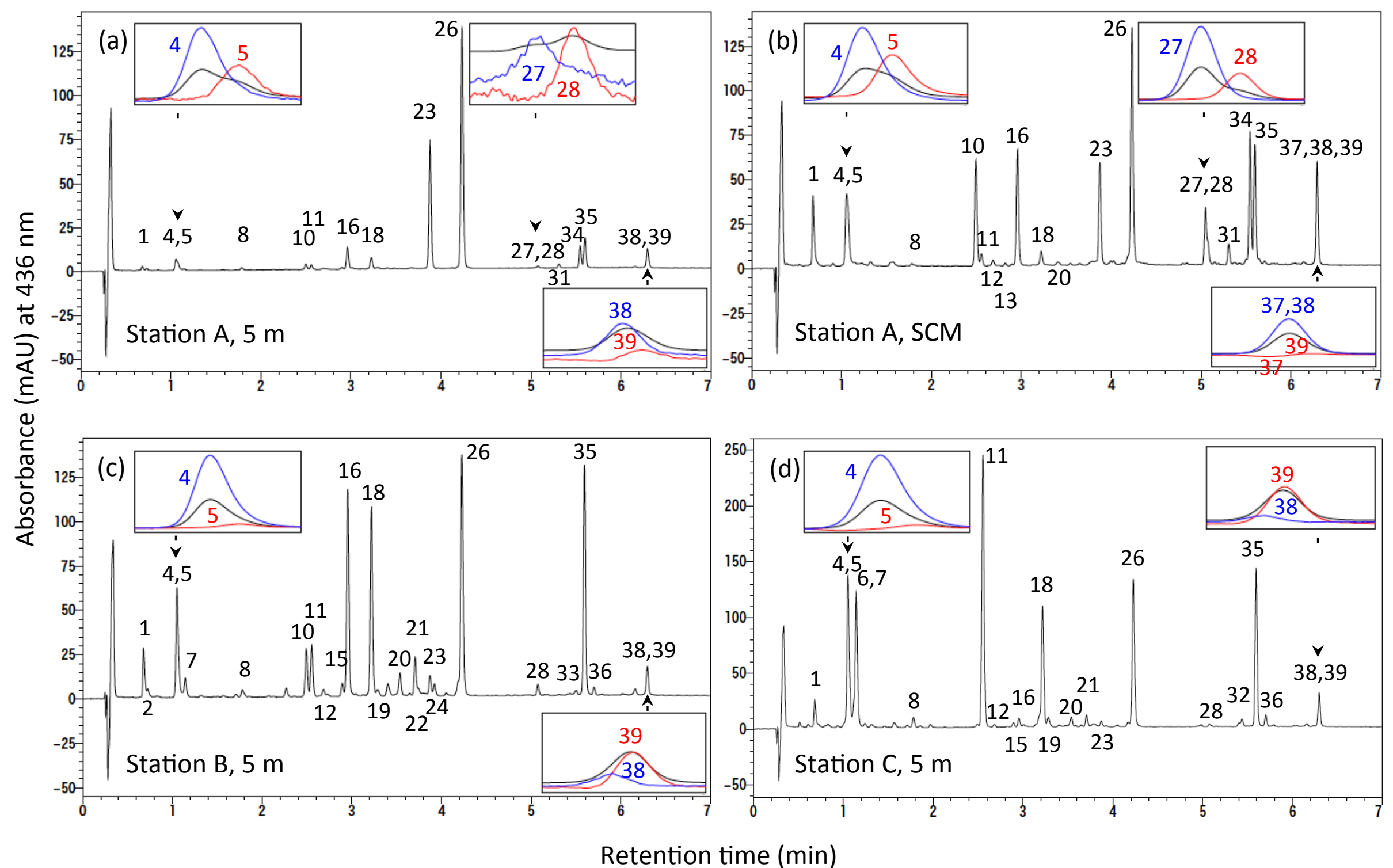

Fig. 5 

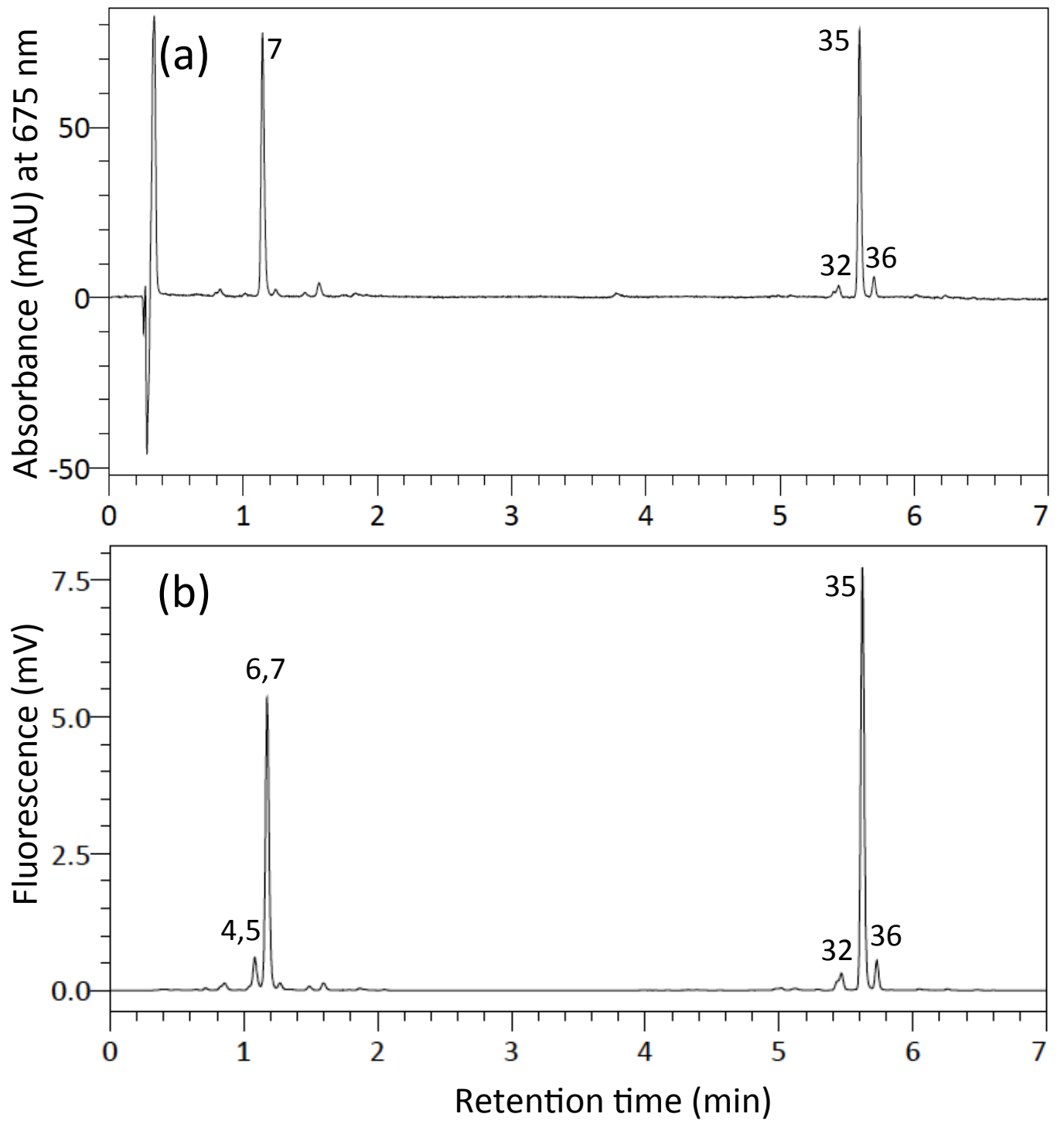

Fig. 6 
Appendix A

Concentrations ( $\mathrm{ng} \mathrm{L}^{-1}$ ) of major chlorophylls and carotenoids at stations in the open North Pacific and the neritic Bering Sea.

\begin{tabular}{|c|c|c|c|c|c|c|c|c|c|}
\hline Station & Depth $(\mathrm{m})$ & $\mathrm{Chl} c_{3}$ & $\mathrm{Chl} c_{2}$ & MgDVP & Chlide $a$ & Peri & But-fuco & Fuco & $c-\mathrm{Neo}$ \\
\hline$A$ & 5 & 2.57 & 2.89 & 1.49 & 1.15 & 2.63 & 3.07 & 3.19 & 0.287 \\
\hline$A$ & 136 & 39.8 & 17.4 & 11.0 & 0.909 & 6.16 & 52.8 & 7.22 & 2.82 \\
\hline$B$ & 5 & 25.0 & 27.2 & 1.40 & 12.3 & 11.3 & 25.3 & 29.4 & 2.94 \\
\hline C & 5 & 52.5 & 127 & 7.26 & 315 & 37.6 & 6.94 & 530 & 4.02 \\
\hline Station & Depth (m) & Pras & Viola & Hex-fuco & Diadino & Allo & Diato & Zea & Lut \\
\hline$A$ & 5 & N.D. & 0.827 & 12.2 & 4.43 & N.D. & N.D. & 50.4 & N.D. \\
\hline$A$ & 136 & 1.17 & 0.669 & 63.2 & 6.36 & 0.199 & N.D. & 39.1 & 0.190 \\
\hline$B$ & 5 & N.D. & 4.41 & 112 & 67.8 & 8.45 & 14.0 & 7.99 & 4.73 \\
\hline C & 5 & 0.907 & 4.93 & 13.8 & 136 & 16.1 & 14.8 & 4.75 & 0.432 \\
\hline Station & Depth $(m)$ & DVCh $b$ & Chl $b$ & $\alpha$-Cryp & DVChl a & Chl a & $\beta \varepsilon$-Car & $\beta \beta$-Car & \\
\hline$A$ & 5 & 5.78 & 8.65 & 1.24 & 17.9 & 30.9 & 5.94 & 1.46 & \\
\hline$A$ & 136 & 460 & 132 & 6.33 & 119 & 126 & - & - & \\
\hline$B$ & 5 & N.D. & 81.8 & N.D. & N.D. & 226 & 2.09 & 5.35 & \\
\hline C & 5 & N.D. & 56.4 & N.D. & N.D. & 555 & 4.59 & 24.5 & \\
\hline
\end{tabular}

N.D. and - indicate not detected and not determined, respectively. 